and Geotechnics

Elsevier Editorial System(tm) for Computers

Manuscript Draft

Manuscript Number: COGE-D-15-00438R2

Title: DEM modelling of cone penetration test in a double-porosity crushable granular material

Article Type: Research Paper

Keywords: Discrete element method, pumice sand, cone penetration, particle crushing, double porosity

Corresponding Author: Dr. Matteo Oryem Ciantia, Ph.D.

Corresponding Author's Institution: Universitat Politècnica de Catalunya

First Author: Matteo Oryem Ciantia, Ph.D.

Order of Authors: Matteo Oryem Ciantia, Ph.D.; Marcos Arroyo; Joanna Butlanska ; Antonio Gens

Abstract: A three-dimensional discrete element model is used to investigate the effect of grain crushing on the tip resistance measured by cone penetration tests (CPT) in calibration chambers. To do that a discrete analogue of pumice sand, a very crushable microporous granular material, is created. The particles of the discrete model are endowed with size-dependent internal porosity and crushing resistance. A simplified Hertz-Mindlin elasto-frictional model is used for contact interaction. The model has 6 material parameters that are calibrated using one oedometer test and analogies with similar geomaterials. The calibration is validated reproducing other element tests. To fill a calibration chamber capable of containing a realistic sized CPT the discrete analogue is up-scaled by a factor of 25. CPT is then performed at two different densities and three different confinement pressures. Cone tip resistance in the crushable material is practically insensitive to initial density, as had been observed in previous physical experiments. The same CPT series is repeated but now particle crushing is disabled. The ratios of cone tip resistance between the two types of simulation are in good agreement with previous experimental comparisons of hard and crushable soils. Microscale exploration of the models indicates that crushing disrupts the buttressing effect of chamber walls on the cone. 


\section{DEM modelling of cone penetration tests in a double-porosity 2 crushable granular material}

3

4

5

6

7

13 is validated reproducin

\section{ABSTRACT}

Matteo Oryem Ciantia, Marcos Arroyo, Joanna Butlanska \& Antonio Gens Departamiento de Ingeniería del Terreno,UPC, Barcelona, Spain, - matteo.ciantia@upc.edu

A three-dimensional discrete element model is used to investigate the effect of grain crushing on the tip resistance measured by cone penetration tests (CPT) in calibration chambers. To do that a discrete analogue of pumice sand, a very crushable microporous granular material, is created. The particles of the discrete model are endowed with sizedependent internal porosity and crushing resistance. A simplified Hertz-Mindlin elastofrictional model is used for contact interaction. The model has 6 material parameters that are calibrated using one oedometer test and analogies with similar geomaterials. The calibration

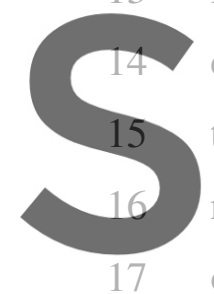
containing a realistic sized CPT the discrete a
then performed at two different densities and
resistance in the crushable material is practic observed in previous phys
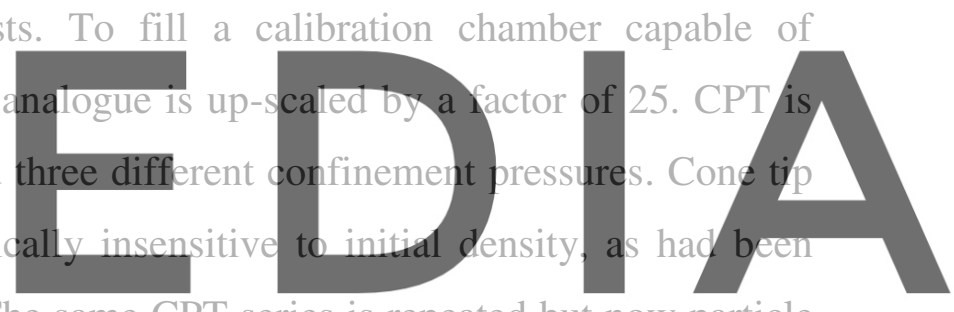

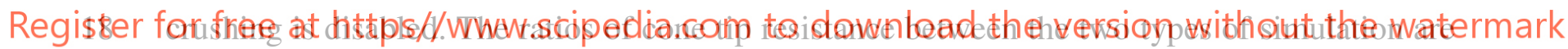

19 in good agreement with previous experimental comparisons of hard and crushable soils.

20 Microscale exploration of the models indicates that crushing disrupts the buttressing effect of 21 chamber walls on the cone.

\section{KEY WORDS:}

23 Discrete element method, pumice sand, cone penetration, particle crushing, double porosity 


\section{1. Introduction:}

25

26

27

28

29

30

31

32

33

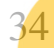

35

36 double porosity materials,

observation. Almeida

relative soil density

observed by Wesley 2

case of that phenomenon: cone tip resistance measured in the calibration chamber appeared

42 confining pressure, $\sigma_{\mathrm{v}}$ of $200 \mathrm{kPa}$ ).

43 If strong-sand based correlations are used to interpret CPT results on more fragile soils

44 relative density and frictional strength will be underestimated. This has large implications for

45 CPT-based quality control procedures of soil treatments (Wehr, 2005). Particle crushing 46 induced during CPT is also problematic when CPT-based field estimates of liquefaction are 47 compared with laboratory tests (Moss, 2014) or when correlating CPT with other in situ test 48 results, such as the SPT (Ahmed et al. 2014). 


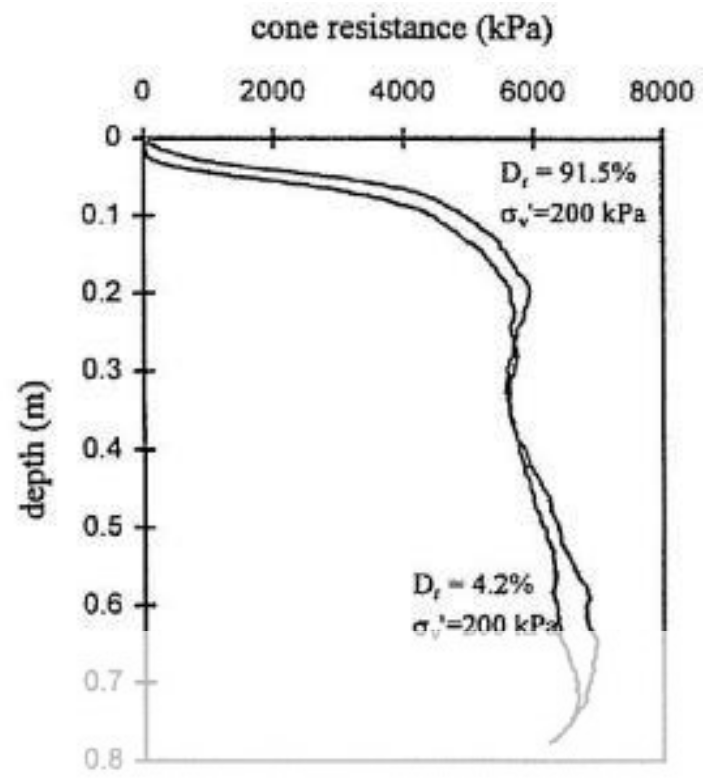

Figure 1 Calibration chamber CPT results on pumice sand as reported by Wesley (2007). Depth is measured with respect to the top of the calibration chamber

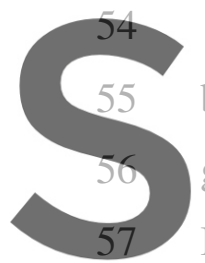

\section{Addressing this}

but slow and costly.

grain strength; sands

It is then desirable to
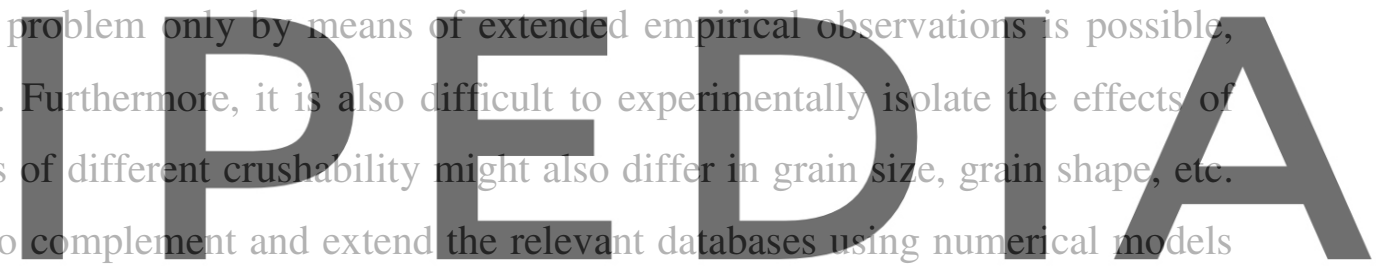

58 that can represent and isolate the effect of grain crushability. Several approaches based on Register for free at https//www.scipedia.com to download the version without the watermark

59 suitably formulated continuum models are possible (Zhang et al. 2013; Meier \& Wehr, 2014).

60 Another possibility is to use the discrete element method, which is well adapted both to

61 incorporate micro-scale information and to represent problems involving large displacements

62 such as the CPT (Lobo-Guerrero \& Vallejo, 2005; Arroyo et al. 2011; McDowell et al. 2012;

63 Quezada et al. 2014; Butlanska et al. 2014a).

64 The authors have recently proposed and tested a crushable soil DEM modelling approach 65 that showed good ability to reproduce macroscopic responses of a variety of soils, (Ciantia et 66 al. 2014a, 2015). The model was later extended to include double porosity granular materials

67 (Ciantia et al. 2014b). The extended model is here applied to create a discrete analogue for the 68 volcanic pumice sand tested by Wesley (2007).

69 In what follows we describe first the modelling approach employed to represent crushing in DEM models. Particular detail is given to describe how internal particle porosity is taken 
71 into account. Calibration and validation of the model with laboratory specimen tests is then 72 presented. Finally a calibration chamber (CC) model is built in which a series of CPT 73 analogous to those reported in Wesley (2007) are performed. Test results are mostly examined 74 in terms of observed macroscopic responses, although some particle-scale results are also 75 discussed. All the numerical models described here were built using the PFC3D code (Itasca, 76 2010).
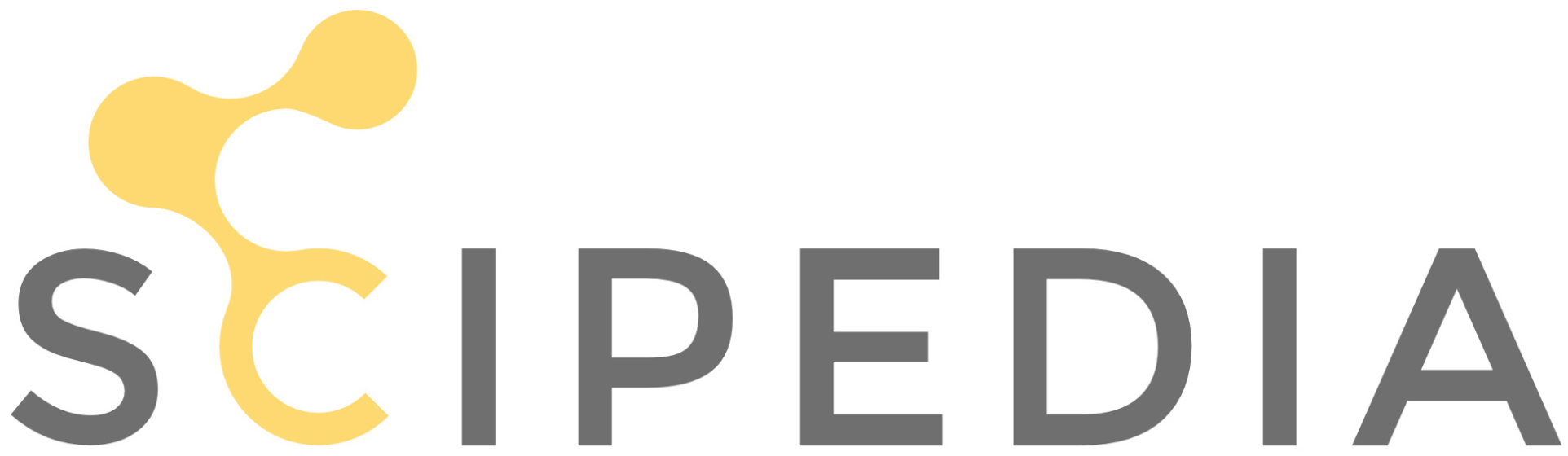

Register for free at https//www.scipedia.com to download the version without the watermark 


\section{8 \\ 2. A crushable DEM model}

Grain crushing may be modeled using the discrete element method (DEM) via two alternative methods: (1) replacing broken elements with new, smaller ones or (2) by using

81 breakable element agglomerates. The latter is helpful for a detailed understanding of the 82 micromechanics of grain failure (Cheng et al. 2003; Bolton et. al. 2008; Zhao 2013; Zhao et 83 al. 2015). The former is more practical for the modeling of larger scale problems as shown by 84 several examples in 2D (Lobo-Guerrero \& Vallejo, 2005; Ben-Nun \& Einav, 2010) and 3D 85 (Bruchmüller et al. 2011; Esnault \& Roux, 2013). The approach followed here is that of single 86 grain replacement.

87

\subsection{Particle failure}

The failure criteria used in the model was inspired by Russell \& Wood (2009) and Russell 90 et al. (2009). These authors combined a two-parameter material strength criterion with the

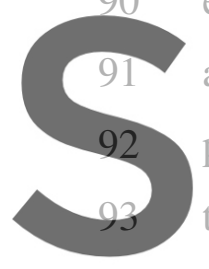

analysis of the elastic stress distribution induced by point practical failure criterion. Withor the final result of their analysis

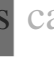

coordination number, a particle subjected to a set of external point forces will reach failure

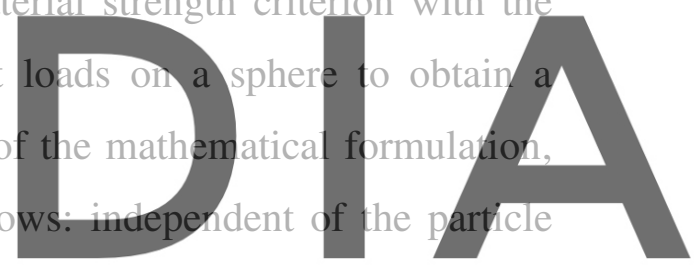

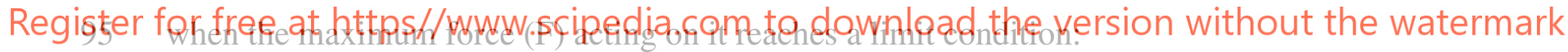

96

97

98

99

100

$$
F \leq \sigma_{\lim } \pi r^{2} \sin ^{2} \theta_{0}=\sigma_{\lim } A_{F}
$$

where $\sigma_{\text {lim }}$ is the limit strength of the material, $r$ is the particle radius and $\theta_{0}$ is half of the solid angle "seen" from the center of the particle which defines the small area of stress application, $A_{F}$ (Figure 2). As indicated in Eq. (1) the limiting force is obtained as the product of a limit strength value, $\sigma_{\text {lim }}$, dependent on material parameters, and a contact area $A_{F}$. 


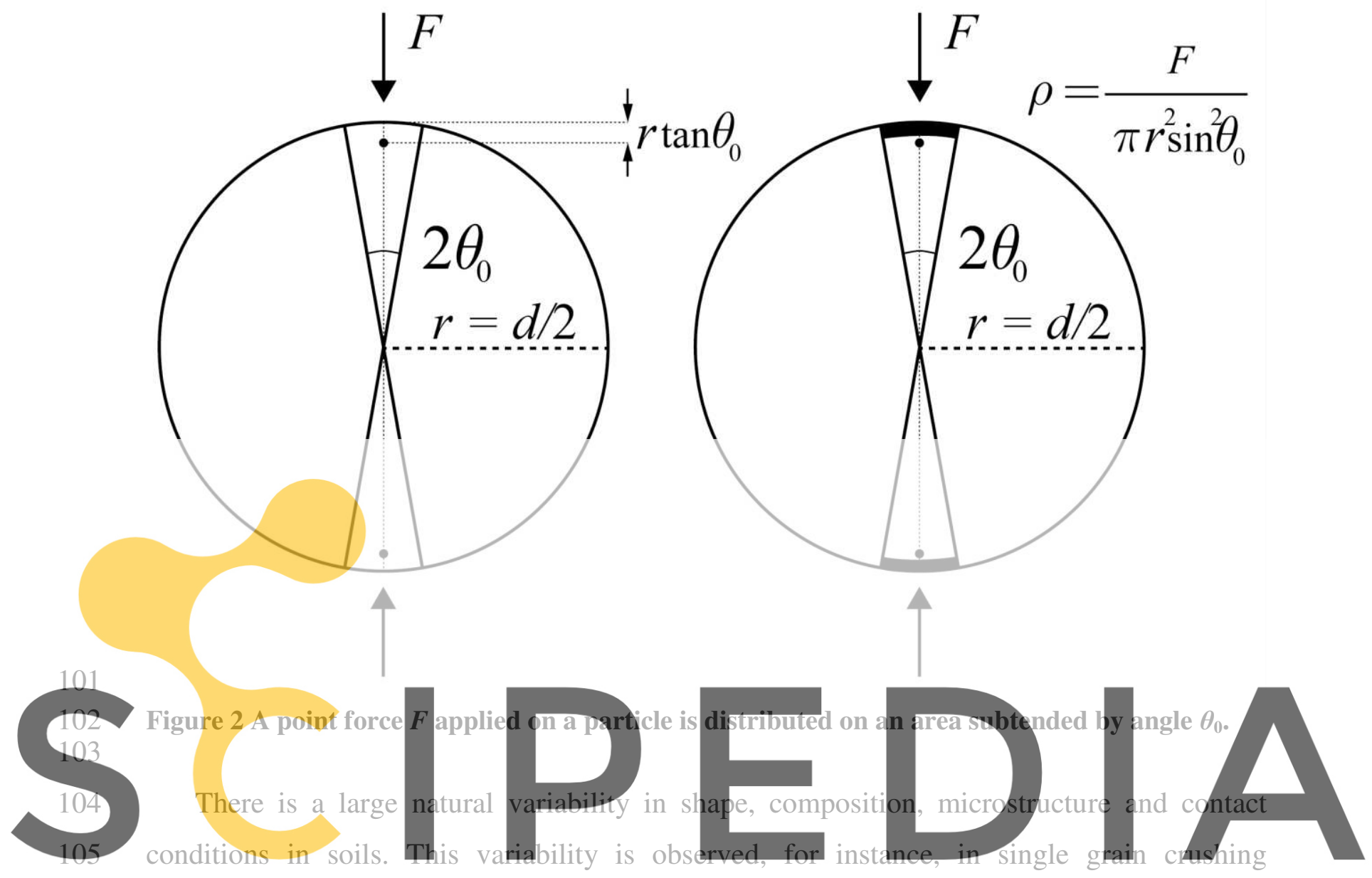

Register for free at https //WWW.scipedia.com to download the version without the watermark

107 size, and as a size dependency of the average strength values. To incorporate that variability

108 into the model, the limit strength, $\sigma_{l i m}$, is assumed to be normally distributed for a given

109 sphere size. This effect is incorporated as a dependency of the mean strength value through a

110 correction factor, $f_{l}$. The coefficient of variation of the distribution (var) is design as a

111 material parameter.

112 It has been repeatedly observed in single-particle crushing experiments that smaller

113 particles are stronger than larger ones. This size effect in particle strength is incorporated as a

114 dependency of the mean strength value on particle diameter through a second correction

115 factor, $f_{2}$. This correction factor is casted in a Weibull-like form, Eq. (2). However, the

116 Weibullian statistics for strength (Weibull, 1951) are not assumed, and $m$ and var are

117 independent parameters (Jansen \& Stoyan, 2000; Brzesowsky et al, 2011). Following

118 McDowell \& Bono (2013), Eq. (2) may be simply described as a hardening rule. 


$$
\begin{aligned}
& \sigma_{\lim }=\sigma_{\lim , 0} f_{1}(\text { var }) f_{2}(d) \\
& f_{2}(d)=\left(\frac{d}{d_{0}}\right)^{-3 / m}
\end{aligned}
$$

where $m$ is a material parameter and $\sigma_{\lim , 0}$ the mean limit strength at $d_{0}$, which is the 122 reference diameter (here chosen as $2 \mathrm{~mm}$ ).

123 To evaluate the contact area $A_{F}$ in Eq. (1) Hertzian contact theory is applied. For smooth 124 spheres the radius of the contact area is:

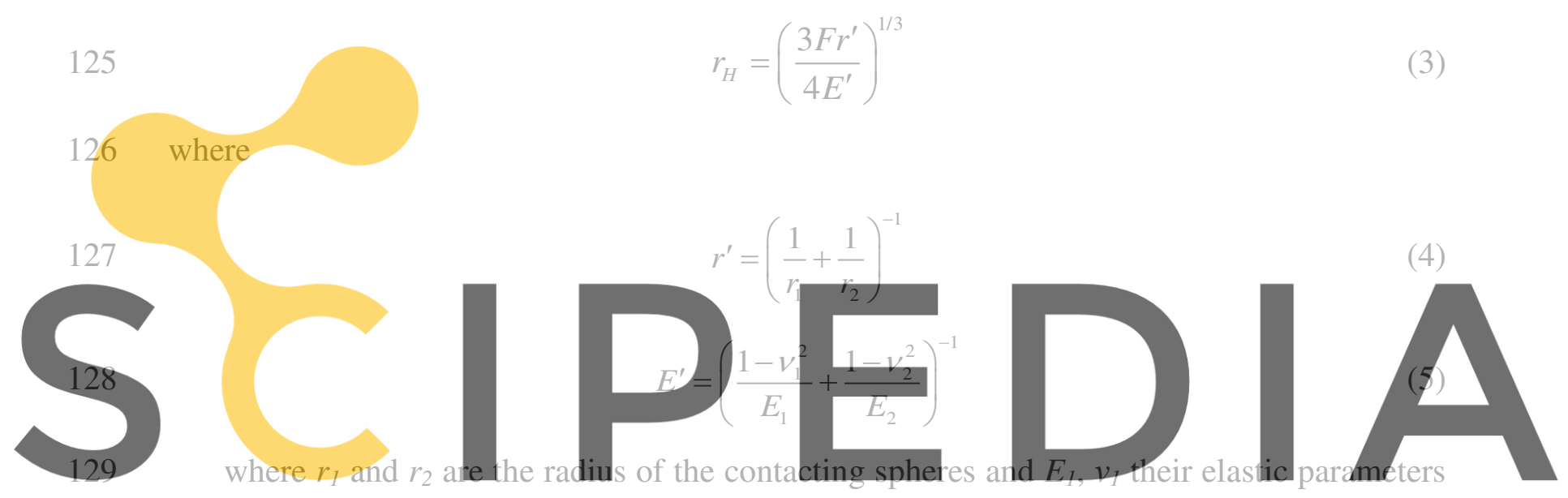

\subsection{0 (Young modulus and Poisson ratio respectively).}

Register for free at https//wwW.scipedia.com to download the version without the watermark

$$
F \leq\left[\sigma_{\lim , 0} f_{1}(\operatorname{var})\left(\frac{d}{d_{0}}\right)^{-3 / m} \pi\left(\frac{3 r^{\prime}}{4 E^{\prime}}\right)^{2 / 3}\right]^{3}
$$

This can be easily implemented into the PFC3D code using a FISH routine.

\subsection{Particle splitting and lost mass}

Once the limit condition is reached, a particle, modeled with a sphere in PFC, will split

137 into smaller prescribed tangent spheres. It is clear that this way of modeling crushing does not

138 conserve the mass within the numerical simulation. This is acceptable if it is assumed that the

139 mass loss is formed by finer particles that have a small influence on the macroscopic

140 mechanical response. Indeed, smaller particles do have a lesser role than large ones on force

141 transmission through a granular mass (Mihn \& Cheng 2013, Esnault, \& Roux 2013). 
142 With the help of auxiliary rules, the mass loss on crushing can be accounted for at the 143 post-processing stage. For instance, the full evolution of grain size distribution (GSD) during 144 element test can be estimated if the deleted volume is assumed to have a specific particle 145 distribution. Here, a fractal distribution (Einav, 2007) with maximum particle size smaller 146 than the smallest particle produced during the crushing event is assumed for that purpose.

147 Ciantia et al. (2015) detailed this procedure and compared the effect of an alternative 148 splitting configurations on element test response. Authors concluded that the 14-ball crushed 149 configuration represented in Figure 3 (47\% volume of mother particle is deleted at each 150 crushing event) was accurate enough to reproduce the macroscopic response of element tests.

151 Since breakage only happens to a fraction of particles during test, the total volume loss for a

152 granular ensemble is much smaller than this single-particle value (see discussion section).
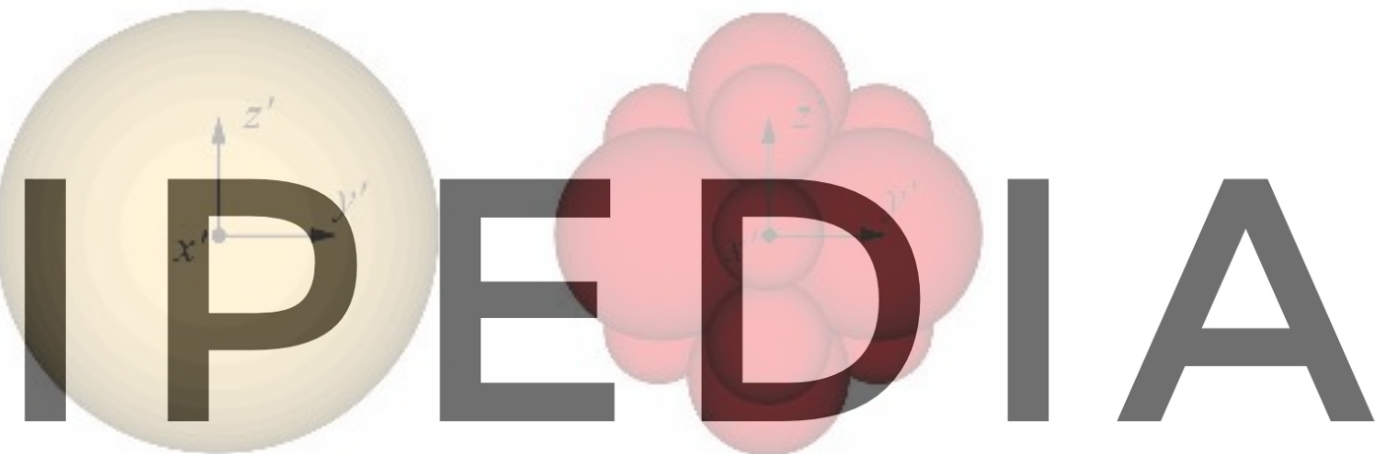

Register for free at https//www.scipedia.com to download the version without the watermark

154 Figure 3 a) Initial particle, b) Particle splitting configuration

155

156 After breakage, the newly created particles inherit the velocity and material parameters of the

157 mother particle except for the intrinsic strength $\left(\sigma_{\lim , 0}\right)$ that is randomly assigned respecting 158 normal distribution criteria. To limit the computational cost of crushing procedures in DEM it 159 is common practice to restrict its application to particles above a certain minimum particle 160 size, $d_{\text {limit }}$ (Cheung et al. 2003; Marketos \& Bolton, 2009; Esnault \& Roux, 2013). To allow 161 enough breakage to develop $d_{\text {limit }}$ is always below the maximum daughter diameter of a 162 particle with the initial median particle diameter, $D_{50}$. 
166

167

168

169

170 where $F_{n}$ and $F_{t}$ are, respectively, the normal and shear contact force components, $\phi$ is the

171 interparticle friction angle. The simplified Hertz-Mindlin contact model is used to represent

172 non-linear contact stiffness

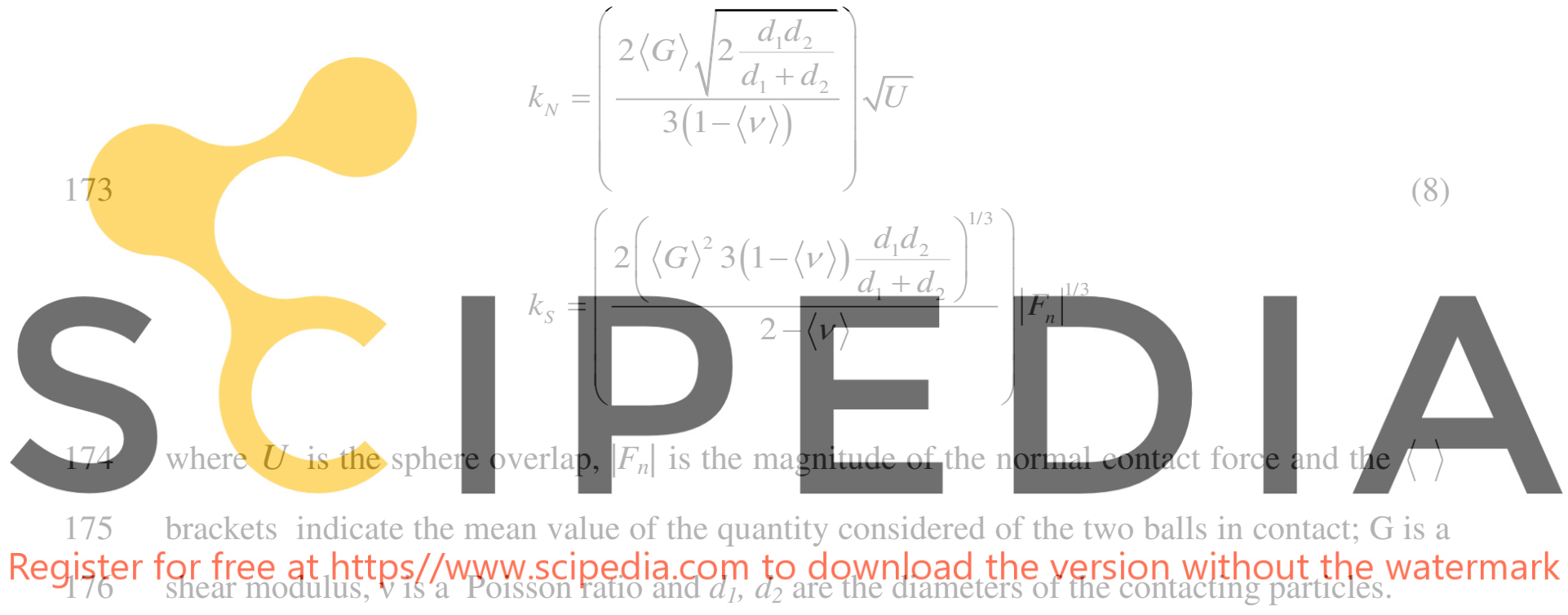

177 Discrete element rotation was inhibited to roughly mimic the effect of the very angular shape

178 of pumice sand. This approach, which can be traced back to Ting et al. (1989), has been

179 successfully applied in previous models of angular granular materials (Arroyo et al. 2011).

180

181

2.4 Upscaling procedure.

182 Scaling up the particle size while maintaining constant other geometrical dimensions of the

183 problem substantially reduces the number of particles in the model (Figure 4). An upper limit

184 to particle scaling is given by the relevant dimensions of the model. A sufficiently large

185 number of particles should remain so that the granular media response is maintained in an

186 average sense. 
187

188

189

190

191

192

193

194

195

196

197

198

199

200

201

202

203

204

205
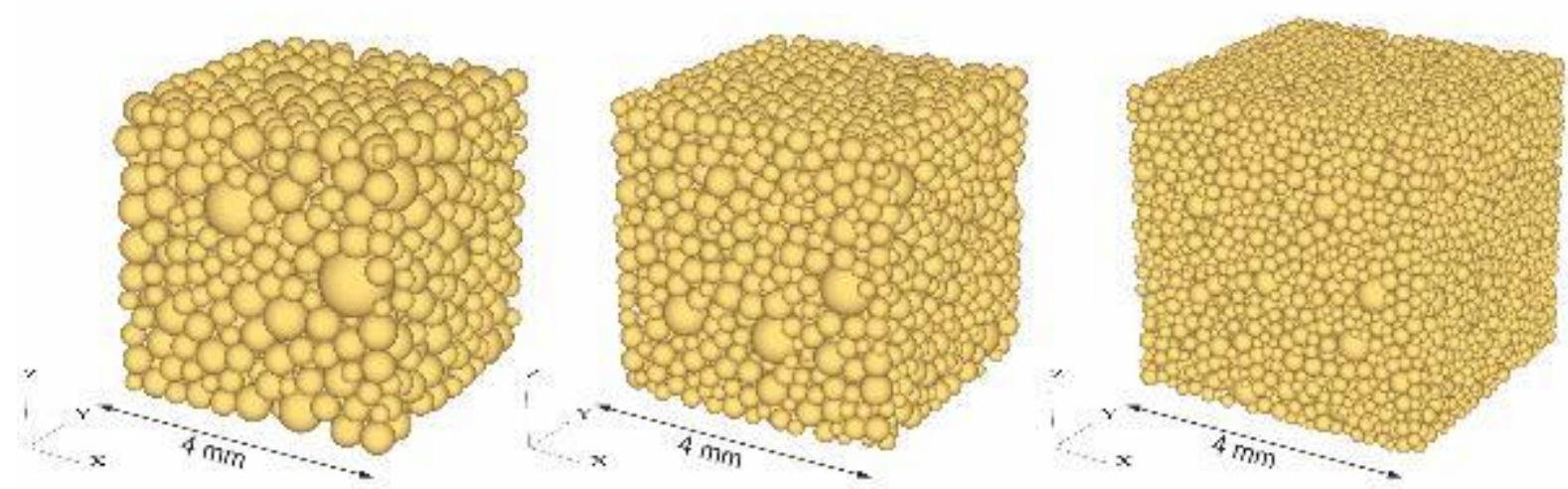

Figure 4 Scaled-up specimens for triaxial testing. (left) Scale factor $=2$ corresponding to 1304 particles, (center) scale factor $=\mathbf{1 . 5}$ corresponding to 3084 particles, and (right) scale factor $=1$ corresponding to 10397 particles.

A successful upscaling procedure should preserve the macroscopic responses of interest such as compressibility, apparent yield stress, etc. Ciantia et al. (2015) showed that this is the case for the given model if the following scaling rules are applied:

a) Particle strength: The scale factor $\mathrm{N}$ is just factored in the definition of the reference dimension $d_{0}$.

$$
f_{2}=\left(\frac{d}{\mathrm{~N} d_{0}}\right)^{-3 / m}
$$

b) Stiffness: Gabrieli et al. (2009) reason that macroscopic stiffness is invariant on scaling if contact stiffness is proportional to particle dimensions. That is an inbuilt characteristic of the simplified Hertz-Mindlin formulation described in Eq. (8) and no modification is needed.

c) Grain Size Distribution: Uniform scaling of particle size shifts the GSD line towards the right proportionally to the scaling factor $\mathrm{N}$. To compare GSD evolutions of the same test with different scaling factors all GSD are divided by the scale factor $\mathrm{N}$ (downscaling procedure). 
206

207

208

209

210

211

212

213

214

215

$216 \quad n_{\mathrm{int}}(d)=1-\frac{G_{s}(d)}{G_{s 0}}$

Where, $G_{s}(d)$ is the apparent specific gravity of a particle with diameter $d$.

\section{Double porosity granulates}

If a granular material is formed by porous grains the definition of particle mass and volume need to take that into account. An extra complication appears if the porosity of the grains varies with grain size.

\subsection{Internal porosity size dependency}

The reference material in this study is a Pumice sand described by Wesley (2007). Particles of this sand are almost entirely formed by quartz but, because of their internal porosity, they have an apparent specific gravity well below that of quartz $\left(G_{s 0} \sim 2.6\right)$. Moreover, the apparent specific gravity of single sized fractions is not constant. This means that intragranular or internal porosity, $n_{\text {int }}$ is variable with particle diameter, since:

219
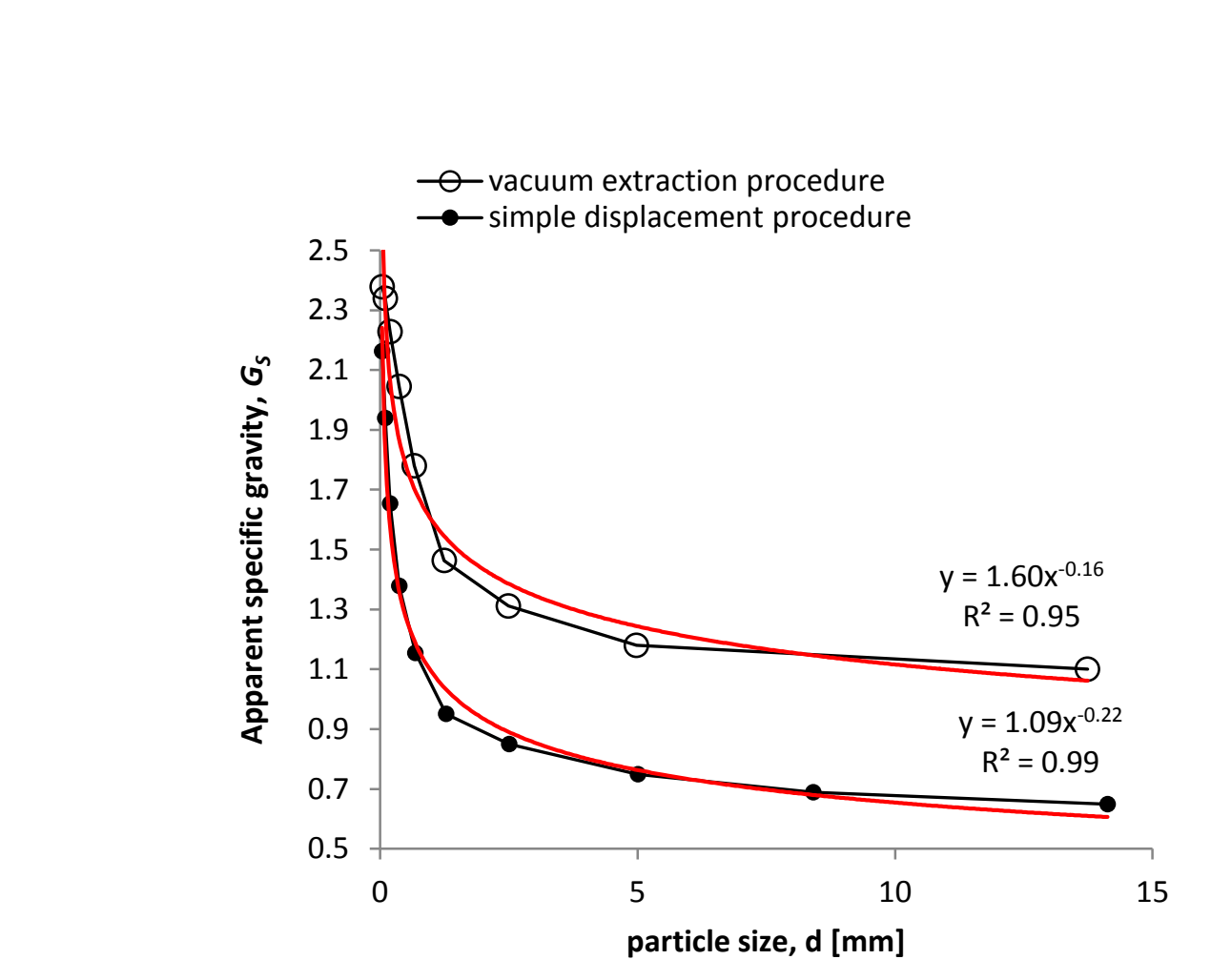

\section{8}

(a) 


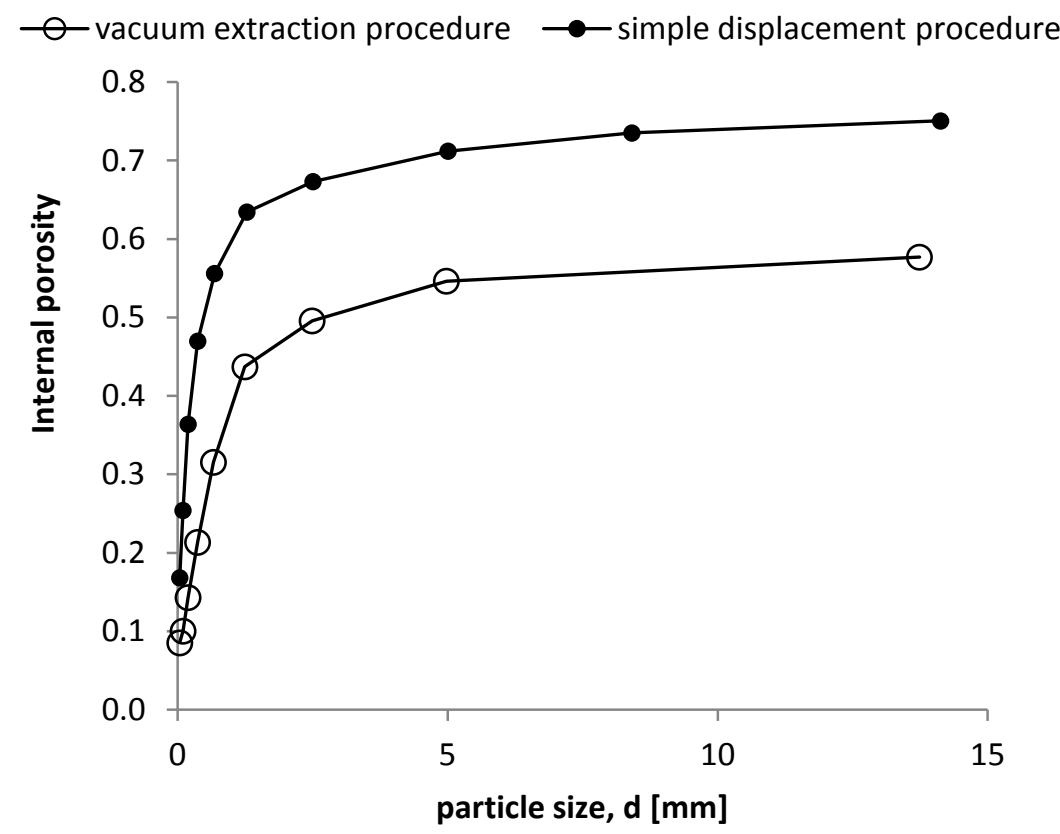

(b)

Figure 5 Crushed pumice single sized fractions a) Apparent specific gravity as a function of particle size, as reported by Wesley (2007) b) internal porosity as a function of particle diameter.

The apparent specific gravity obtained is rather sensitive to the measurement procedure (Wesley, 2001); larger values are obtained if water is forced into the surface connected porosity using vacuum than if vacuum is not applied (Figure 5a). Whatever the measurement method chosen, and similarly to other double-porosity granulates (Casini et al. 2013), the variation of specific gravity with size in this case can be well interpolated by the function:

$G_{s}(d)=A\left(\frac{d}{d_{r e f}}\right)^{-B}$

Where $d_{r e f}$ is a reference diameter $(1 \mathrm{~mm}), d$ is particle diameter and $A, B$ are the curve parameters indicated in Figure 5a. Using Eq. (10) and the experimental results of Figure 5a it is possible to plot the dependency of internal porosity on particle diameter (Figure 5b).

\subsection{Intergranular and intragranular porosity}

To incorporate internal porosity in the DEM model, the internal porosity, $n_{\text {int }}$ of a single particle, $p$, is defined as: 
$239 \quad n_{\mathrm{int}}^{p}=\frac{V_{V}^{p}}{V_{T}^{p}}$

240 Where $V_{V}^{p}$ is the volume of the voids within particle $p$, while $V_{T}^{p}$ is the total volume of 241 that particle. Therefore, the solid volume for particle $p$ results:

$242 \quad V_{S}^{p}=V_{T}^{p}\left(1-n_{\text {int }}^{p}\right)$

$243 \quad$ And the total solid volume for a collection of $p$ particles reads

$244 \quad V_{S}=\sum_{p} V_{S}^{p}=\sum_{p} V_{S}^{p}\left(1-n_{\mathrm{int}}^{p}\right)$

245 When a porous granular material fills a container of total volume $V_{T}$, the intergranular 246 porosity, $n^{\text {inter }}$ is the total volume fraction not occupied by particles

$247 \quad n^{\mathrm{inter}}=1-\frac{\sum_{p} V_{T}^{p}}{V_{T}}$

And the intragranular porosity, $n^{\text {intra }}$ is the total volume fraction occupied by internal 249 voids

$250 \quad n^{\mathrm{intra}}=\frac{\sum_{p} V_{V}^{p}}{V_{T}}$

Total porosity is obtained as the sum of intergranular and intragranular fractions, (Casini et al. 2013; Ciantia et al. 2014b)

253 $n=n^{\text {inter }}+n^{\text {int } r a}$

254 Porosity fractions are easily computed in DEM, but not so in the laboratory and some 255 simplifications are in use. Thus, for instance, Wesley (2007) systematically assumed a constant apparent specific gravity, $\bar{G}_{s}$ of 1.77 , or, equivalently, a constant internal porosity of 
$257 \bar{n}_{\text {int }}=0.32$ when interpreting mechanical tests on Pumice sand. Assuming constant internal 258 porosity introduces an approximation in the estimate of intragranular porosity. The difference 259 between the approximate value, $\bar{n}^{\mathrm{int} r a}$, and the exact one is given by a correction term, $\Delta n$

$\bar{n}^{\text {intra }}=n^{\text {intra }}+\Delta n$

261 Within experimental measuring error, total porosity can be exactly deduced from dry unit 262 weight and the material specific gravity $G_{s 0}$ as

$263 n=1-\frac{\gamma_{d}}{\gamma_{w} G_{s 0}}$

264 By analogy, Wesley (2007) reported his tests using an apparent porosity $n^{*}$, deduced from 265 dry unit weight, $\gamma_{d}$, and the assumed apparent specific gravity $\bar{G}_{s}$. We have then

$266 \quad n^{*}=1-\frac{\gamma_{d}}{\gamma_{w} \bar{G}_{s}}$

267 It can be seen (see Appendix) that this apparent porosity value is related to the exact value 268 of intergranular porosity by

$n^{\mathrm{inter}}=n^{*}+\frac{\Delta n}{\left(1-\bar{n}_{\mathrm{int}}\right)}$

\subsection{Internal porosity and particle generation}

The same grain size distribution by weight (Figure 6a) can be obtained using very

273 different hypothesis about internal particle porosity. However, these different hypothesis

274 results in different particle numbers (the volumetric grain size distribution changes, Figure

275 6b) because initial fabric and its evolution through crushing are also dependent on particle

276 size. The initial estimate of internal porosity variation with particle diameter has some effect

277 in the amount of crushing induced during a test.

278 For all the simulations described below, DEM particles were assigned an internal porosity 279 values deduced from simple water displacement measurements of specific gravity on crushed 
280 single-sized fractions of pumice. These are the values reflected in the upper curve of Figure $2815 \mathrm{~b}$. This is based on the assumption that the outside perimeter of the particle determines contact interactions. Hence surface-connected particle porosity should be included within 283 internal element porosity. Other hypothesis may be implemented in the discrete model, if 284 needed.

285
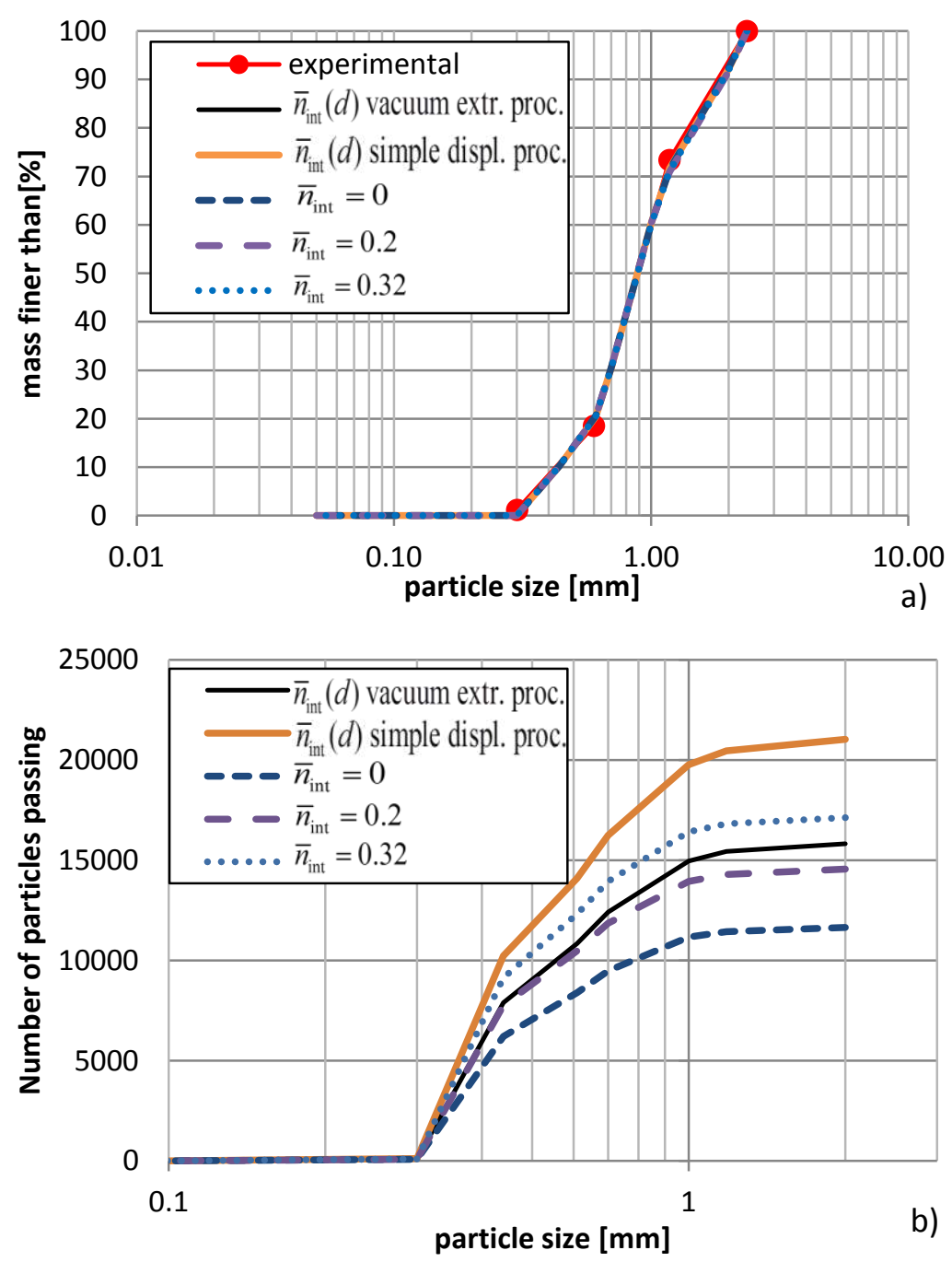


\section{4. Single-specimen response}

292

293

294

295

296

297

298

299

300

301

302

303

304

305

306

307

308

\subsection{Sample preparation and initial conditions}

Cubical discrete specimens with $16 \mathrm{~mm}$ side were created using the radius expansion method (REM). Particle sizes were selected to match the weight cumulative grain size distribution taking into account the internal porosity distribution described by Eq. (11) with $A$ $=1.09$ and $B=0.22$.

After REM finished, velocities were set to zero. Isotropic compression of $5 \mathrm{kPa}$ was used to obtain - by trial and error, using a temporary interparticle friction reduction and disabling crushing- a closer fit to the initial intergranular porosity target, $n^{\text {inter }}$, of each simulation. That target intergranular porosity was obtained from Eq. (21) using the reported apparent porosity of the specimen, $n^{*}$, the $\bar{n}_{\text {int }}=0.32$ value assumed by Wesley (2007) and computing the corresponding correction term, $(\Delta n \approx-0.15)$ for the assumed internal porosity distribution.

\subsection{Calibration}

The parameters to calibrate are: elastic modulus, $(G, v)$, contact friction angle, $(\phi)$, mean limit strength, $\sigma_{\lim , 0}$, strength variability for a fixed size (var, coefficient of variation of the limit strength) and the $m$ modulus controlling the size effect on strength. Calibration is achieved partly by fitting the macroscopic specimen-scale response of selected laboratory tests and partly by using grain-scale information.

As detailed in Ciantia et al. (2015), grain-scale information in the form of single particle crushing tests is particularly useful to calibrate crushing variability. This seems especially pertinent in a material with size-dependent internal porosity, because it is expected that microporosity will exert a major influence in grain strength. Unfortunately, flat platen compression tests on pumice sand for different particle dimensions were not available. It was then necessary to work by analogy with other porous geomaterial: calcarenite. 

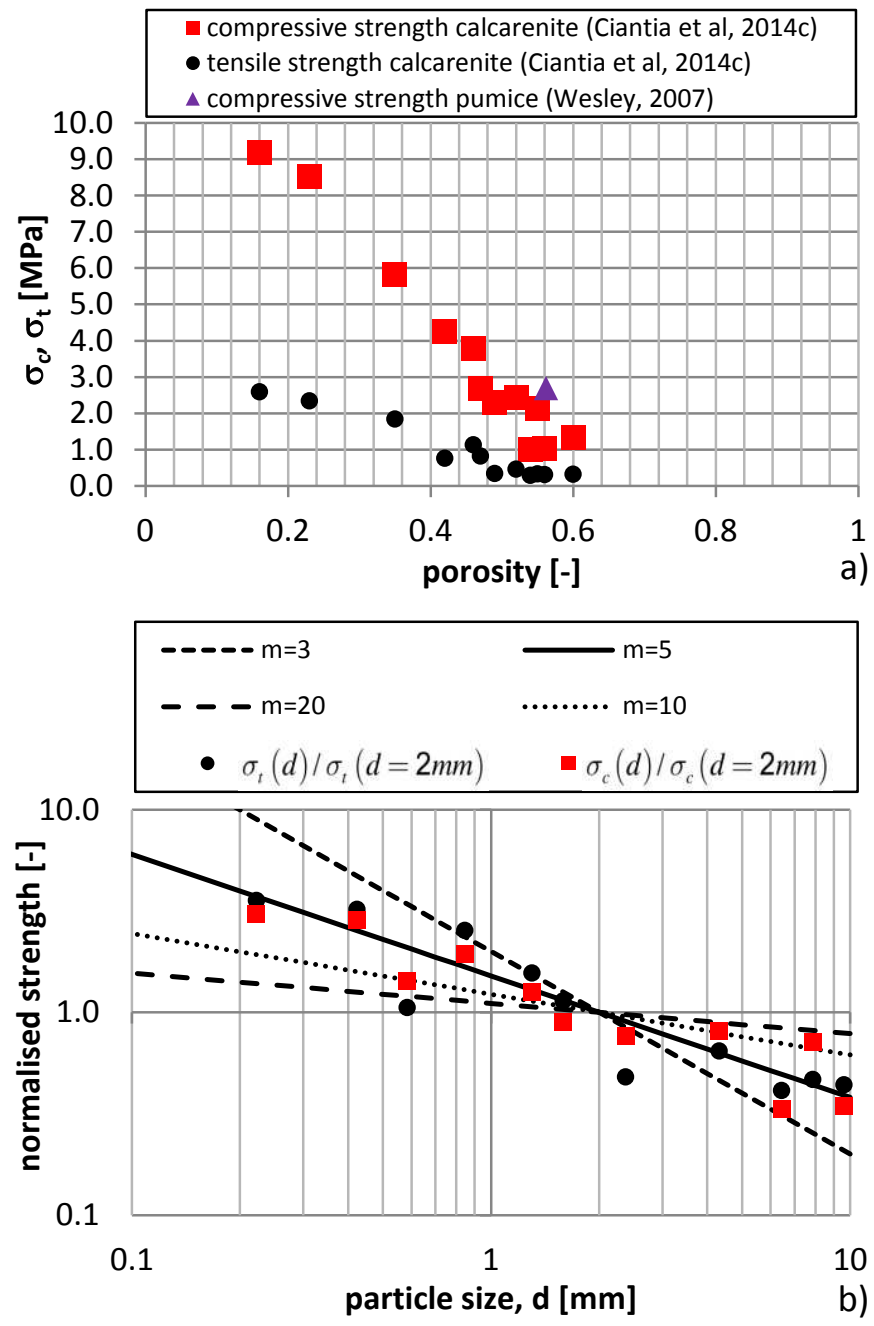

Figure 7 a) Uniaxial compression and indirect tensile strength of calcarenite as a function of porosity and b) normalized strength as a function of equivalent particle size.

The porosity-strength relation for calcarenite rock was experimentally established

322 (Ciantia et al., 2014c) for both the unconfined compression and tensile modes of failure. Data

323 for unconfined compression on a cube of pumice rock was available in Wesley, 2007. It was

324 found that the strength of pumice sand was very close to that of calcarenite specimens with 325 similar porosity (Figure 7a). It was then accepted that the behavior of calcarenite rock 326 specimens offered a good approximation for pumice sand grains, and calcarenite results were 327 then taken as a guide to establish a particle size normalized strength dependency (Figure $7 \mathrm{~b}$ ) 328 from which a value of the $m$ modulus equal to 5 was obtained for the analogue pumice sand.

Wesley (2007) reported results from two oedometers performed on samples with different initial apparent porosity; one loose and one dense. Only the initial apparent porosity, $n^{*}$, was 
331 reported. The total porosity and porosity fractions inferred from this value are collected in

332 Table 1. Loose and dense DEM specimens were created to approximate the initial state of 333 these experiments. Their initial conditions are also reported in Table 1.

334 Several parameters of the contact model were adjusted by fitting model response to the 335 observed response of the loose specimen. Contact friction and elastic properties of the discrete 336 particles $(G$ and $v)$ were selected using the pre-yield section of the oedometric curve. The mean limit strength and within-size strength-variation (parameter var) were selected to fit the macroscopic oedometric yield stress and post-yield slope. The best fit parameters are listed in Table 2. Figure 8 show the comparison of the macroscopic response observed in the experiments and numerical simulations.
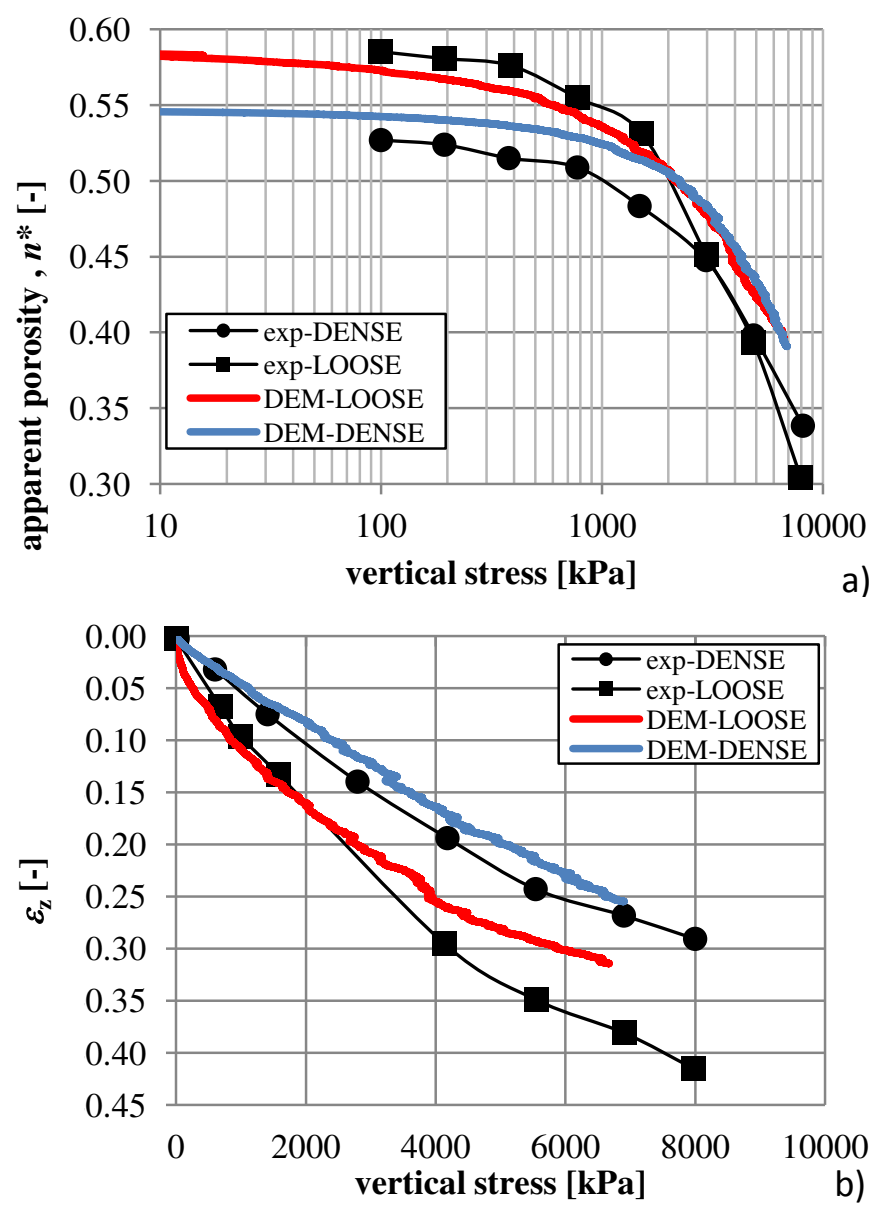

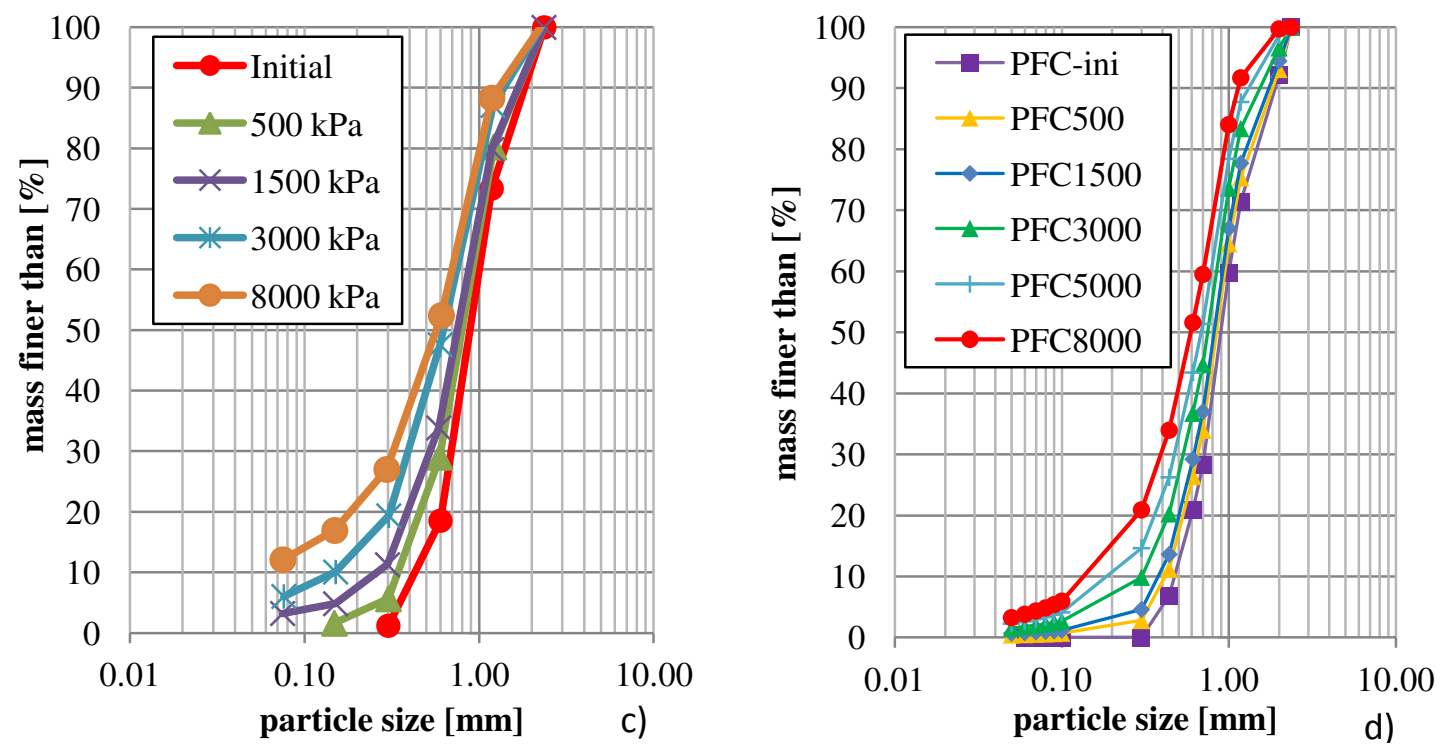

Figure 8 One dimensional compression of pumice sand: evolution of a) apparent porosity $\left.n^{*}, b\right)$ volumetric deformation and c) experimental and d) numerical GSD of the loose sample with vertical stress.

\subsection{Validation}

For validation, the oedometric response of the dense specimen was simulated. The results

352 showed a reasonable agreement with the experimental response (Figure 8). To obtain further

353 validation alongside a different stress path, a series of triaxial compression tests reported by

354 Wesley (2007) at two confining pressures (50 and $300 \mathrm{kPa}$ ) on "loose" and "dense"

355 specimens were also simulated. The initial porosity of "loose" and "dense" triaxial specimens

356 was not reported, and it was therefore assumed equal to that of the corresponding oedometric

357 tests. The numerical simulation results are reported alongside the experimental data in Figure

358 9. Despite some differences, the main traits of the experimental response appear to be well

359 captured by the simulations. 

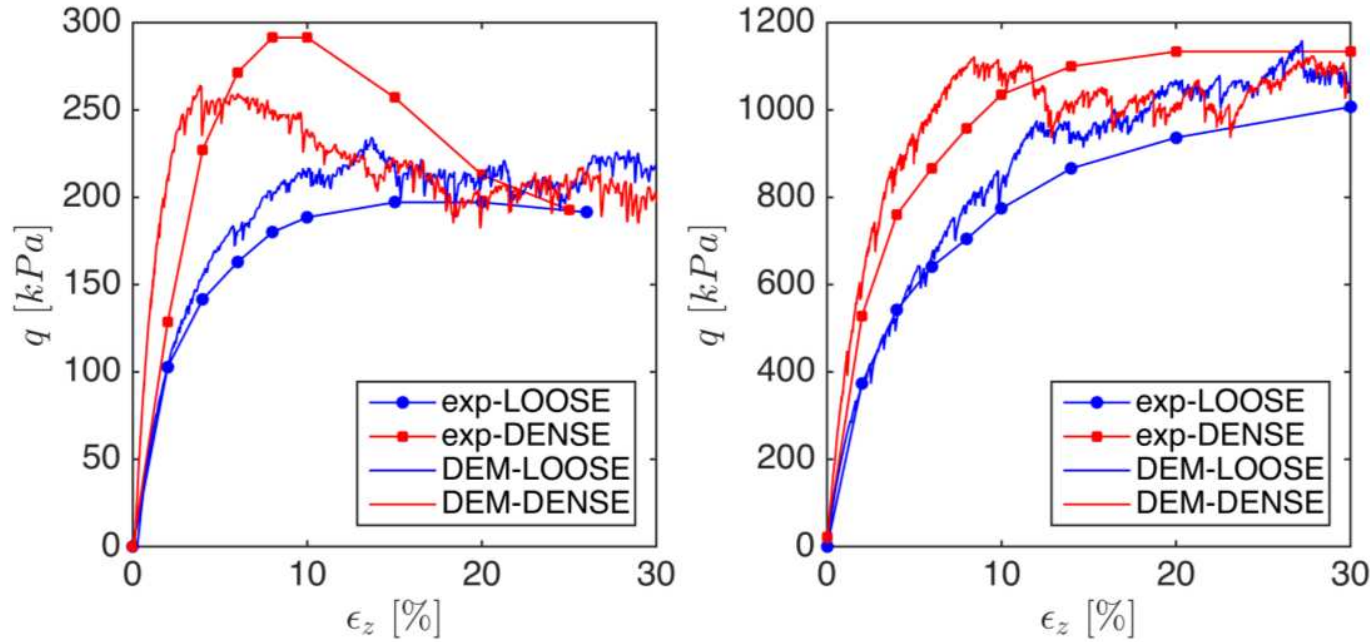

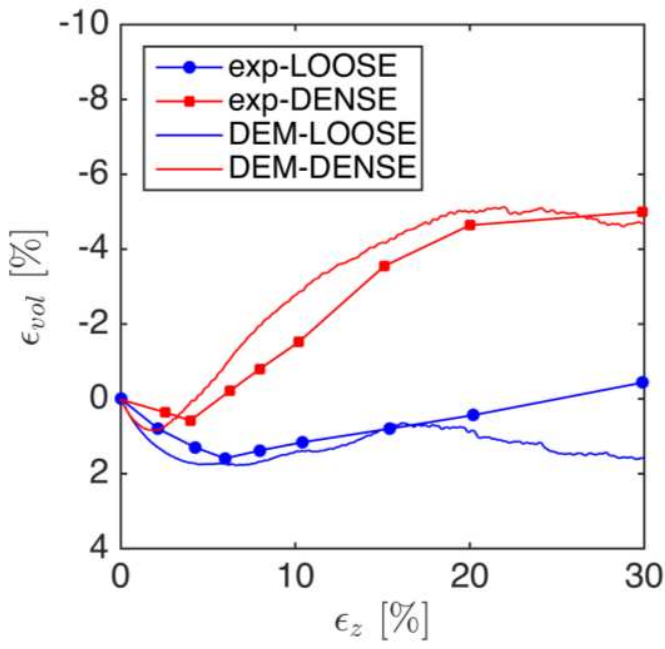

a) $50 \mathrm{kPa}$

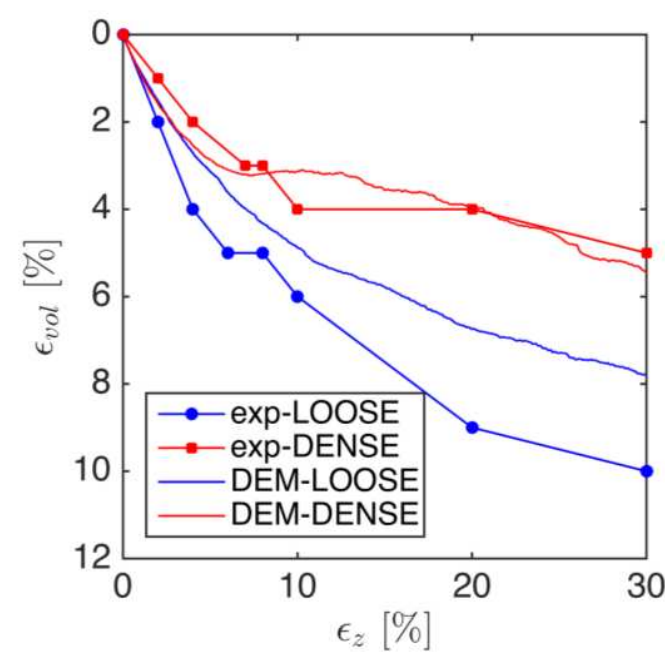

b) $300 \mathrm{kPa}$

Figure 9 Comparison of experimental and numerical triaxial results of loose and dense pumice sand prepared at confining stress of a) $50 \mathrm{kPa}$ and b) $300 \mathrm{kPa}\left(\varepsilon_{\mathrm{z}}, \varepsilon_{\mathrm{vol}}\right.$ are the axial and volumetric strains respectively and $q$ is a deviatoric stress) 


\section{Cone penetration test in pumice sand}

366

\subsection{Model construction}

The calibration chamber (CC) models for CPT were built adapting the procedure described by Arroyo et al. (2011) and Butlanska et al. (2013) to represent, as closely as possible, the conditions used by Wesley (2007) in his physical experiments. A balance between realistic representation and computational affordability is necessary in this type of simulations, because computing time can increase very fast with particle numbers (e.g. McDowell et al. 2012).

In the experiments (Wesley, 2007) pumice sand was placed at the desired density by dry pluviation (loose specimens) or by layered dynamic compaction (dense specimens). Mimicking these procedures in DEM is unpractical; instead the cylindrical chamber was filled with the scaled-up material using the radius expansion method (Itasca, 2010).

To further reduce computational cost one possible approach is to take profit of the cylindrical symmetry of cone and chamber. Frictionless radial walls preventing circumferential motion of particles can be used to enforce this symmetry (McDowell et al., 2012; Lin \& Wu, 2012). Arroyo et al. (2013) showed that rigid radial walls to limit model extent produce some bias towards higher cone resistances. It was thus deemed preferable to optimize model cost only by scaling up some basic problem dimensions. The main dimensions of the experimental and virtual calibration chambers are compared in Table 3. The largest difference between experiment and simulation is the scaled particle size distribution. A factor of 25 is applied to increase particle size in the CPT simulations. The cone size was also scaled-up, by a factor of 2 , to obtain a cone/mean particle ratio, $n_{p}$ close to 3 , similar to the one employed by Arroyo et al. (2011). As shown there, and discussed in more detail elsewhere (Butlanska et al. 2013; Butlanska, 2014b) the main effect of a low $n_{p}$ ratio on the simulation is to increase the noise of the raw penetrograms, which become very jagged. The noise can be filtered out by fitting an appropriate penetration trend line. The following exponential trend has been successfully applied before for that purpose (Arroyo et al. 2011):

$q_{c}\left(h_{p}\right)=a\left[1-\exp \left(-b h_{p}\right)\right]$ 
393 where $q_{\mathrm{c}}[\mathrm{MPa}]$ is a cone resistance, $h_{p}$ is a penetration depth and $a \& b$ are fitting parameters.

394 Parameter $a[\mathrm{MPa}]$ gives the asymptotic or steady state value of cone resistance.

395 The scaled up cone-size resulted in a chamber/cone ratio, $R_{d}$, which was half of that 396 applied in the experiments. The implications of this difference are discussed later.

397 The scaled discrete material filled the chamber with approximately $5.5 \times 10^{4}$ particles. A 398 dimensional analysis of this case similar to that presented in Butlanska et al. (2010b) indicates 399 that, if particle size was not scaled, the number of initial particles filling the chamber would 400 increase by four orders of magnitude. The chamber and cone employed in the simulations are 401 illustrated in Figure 10

402

403

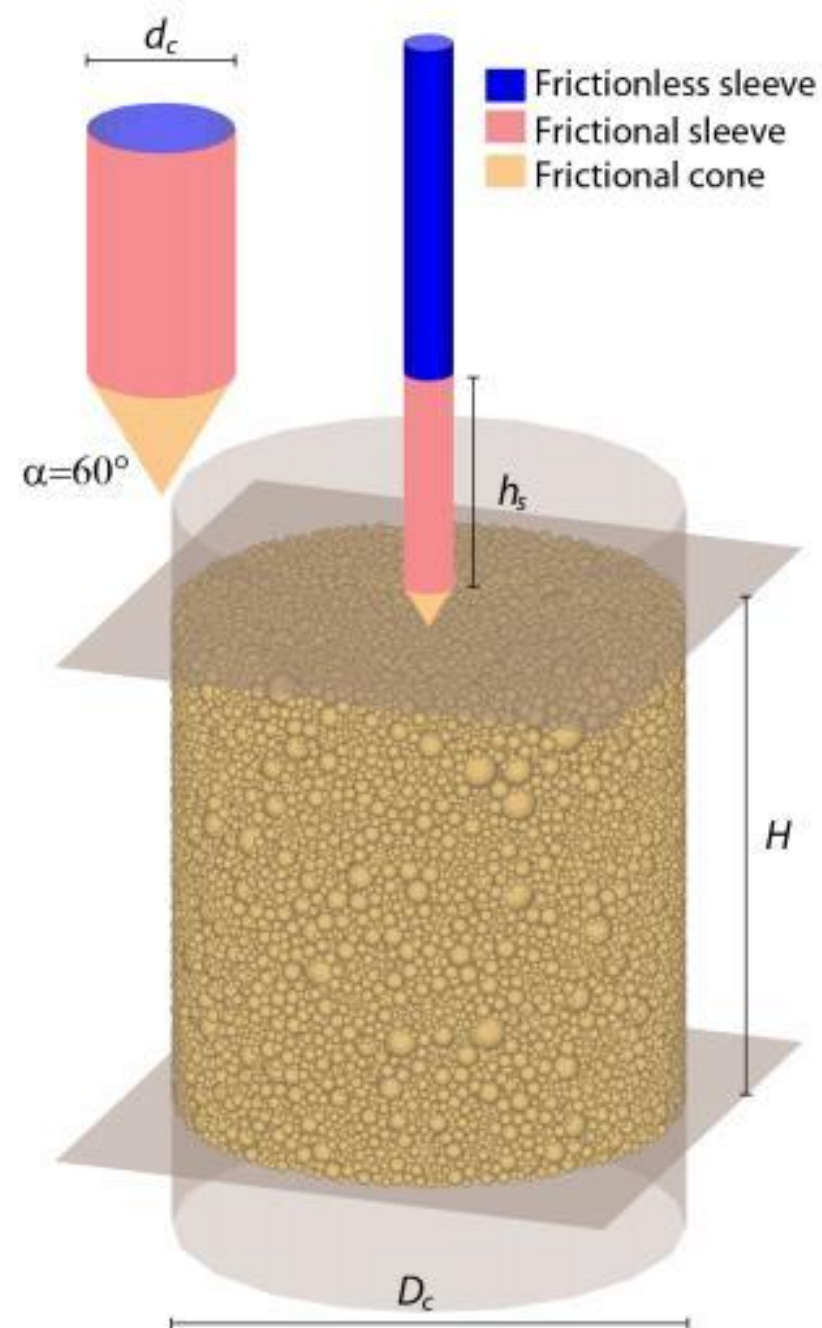

Figure 10 Example geometry before CPT 
407

408

409

410

411

412

413

414

415

416

417

418

419

420

421

422

423

424

425

426

427

428

429

430

431

432

433

434

435

\subsection{CPT simulations}

The calibration chamber CPT described by Wesley (2007) were performed under a nostrain radial lateral condition $(\mathrm{BC} 3: \sigma \mathrm{v}=$ constant, $\varepsilon \mathrm{r}=0)$, with vertical stress constant at the base and a rigid wall on top through which the cone passes. These conditions were replicated in the model, although rigid frictionless walls were used instead of membranes. The bottom horizontal wall is servo controlled to apply the desired vertical stress level.

The cone shaft was modelled using rigid cylindrical walls which, as illustrated in Figure 10, were frictional close to the tip and frictionless far from it. The tip had an angle of 60 degrees and was also frictional with a tip-particle friction coefficient set equal to the interparticle friction. Cone penetration was simulated at a rate of $10 \mathrm{~cm} / \mathrm{s}$. Butlanska et al. (2010a) showed that rates between 2 and $50 \mathrm{~cm} / \mathrm{s}$ do not change the simulation result. The chosen penetration rate is also below the $1 \mathrm{~m} / \mathrm{s}$ limit where dynamical effects are apparent (Quezada et al., 2014; Tran et al., 2014). All the simulations employed a local non-viscous damping coefficient of 0.05 .

Table 4 collects the conditions reported by Wesley (2007) for six CPT tests on pumice sand, alongside those prevailing in the simulations. The test conditions combine two density levels, namely loose and dense and three vertical stress levels. In the experiments both loose and dense conditions varied significantly and were looser than the equivalent conditions for the specimen tests (Table 1). For simplicity, the CC DEM specimens were all formed at two initial densities (at $5 \mathrm{kPa}$ ) used for the element tests. After equilibration stage, onedimensional compression was performed until the target value of vertical stress was attained. The horizontal stress was finally adjusted using a radial wall servo-control until the system was again in equilibrium. A parallel series of 6 CPT DEM tests were performed in specimens formed at the same initial density and taken to the same stress level, but in which particle crushing was not allowed.

\subsection{Macroscale results}

The main result of interest here are the values of cone tip resistance. Figure 11 collects the penetrograms from all the simulations as well as the adjusted penetration curves. Table 5 summarizes the parameters of each adjusted penetration curve. The steady state values of 
436 cone resistance (given by the $a$ parameter of the adjusted penetration curve) are plotted against applied vertical stress in Figure 12.

438 As expected, the small cone diameter-to-mean particle ratio, $\mathrm{n}_{\mathrm{p}}$, results in noisy 439 penetrograms with very strong oscillations (Figure 11). The penetration curves, however, 440 reveal some clear trends. In the crushable material initial density has no discernible effect on 441 cone resistance; when crushing is disabled cone resistance in the denser material roughly 442 doubles that of the looser one. Increasing the boundary vertical stress does increase cone 443 resistance for both the crushable and uncrushable materials, but it does so at a much faster 444 rate in the non-crushable material, particularly if the initial state is dense (Figure 12).

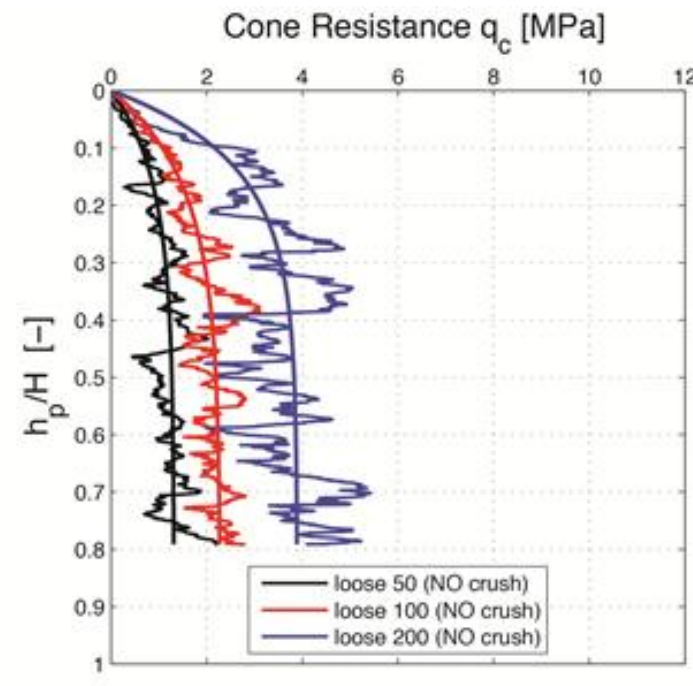

a)

Cone Resistance $\mathrm{q}_{\mathrm{c}}$ [MPa]

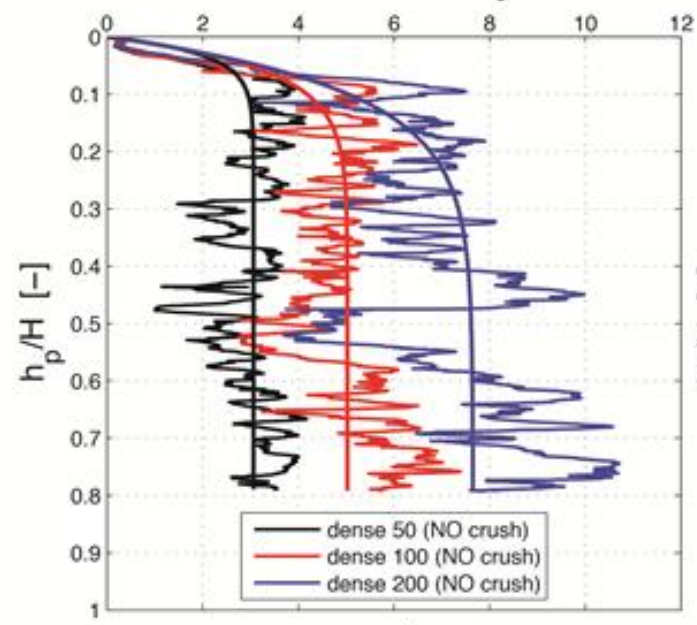

c)
Cone Resistance $\mathrm{q}_{\mathrm{C}}[\mathrm{MPa}]$

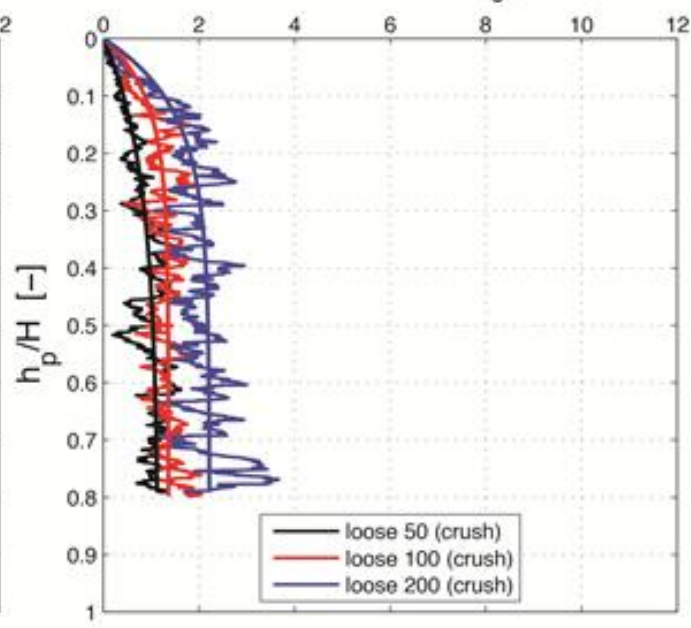

b)

Cone Resistance $\mathrm{q}_{\mathrm{c}}[\mathrm{MPa}]$

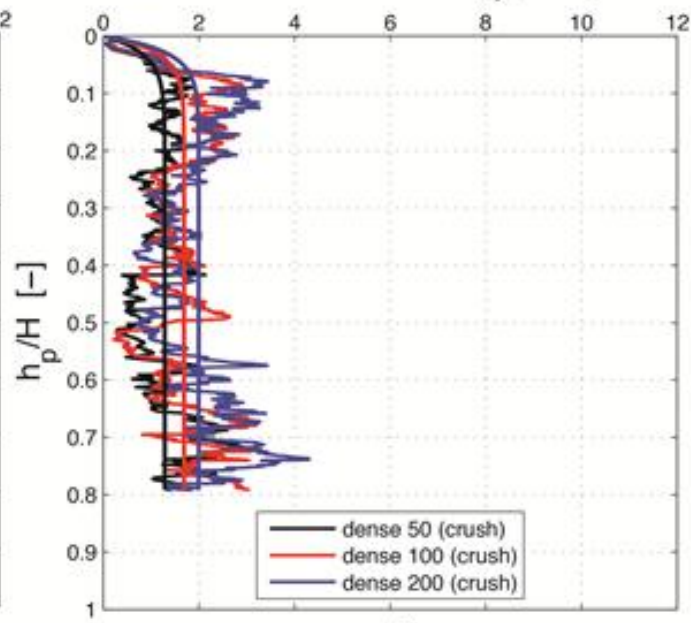

d)
445

446

447

Figure 11 Raw penetrograms and adjusted penetration curves (a) loose uncrushable material (b) loose crushable material (c) dense uncrushable material (d) dense crushable material 


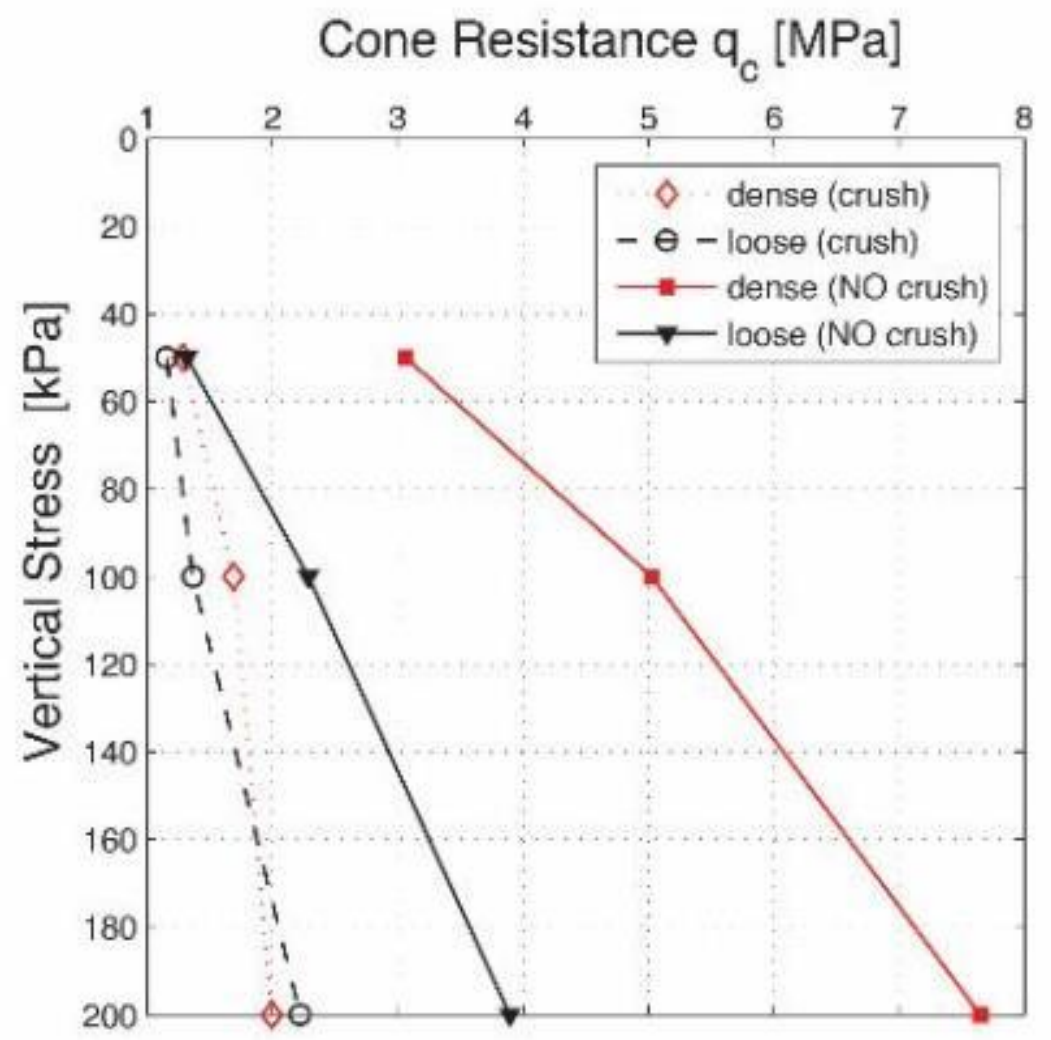

Figure 12 Steady state values of cone resistance vs vertical stress at the base

\subsection{Microscale observations}

As explained by Butlanska et al. (2013) the results of DEM CPT simulations can be examined at several scales. Macroscale results are whole-system responses of direct engineering interest, like the cone tip resistances examined in the previous section. The micro-scale level of resolution describes variables at the highest possible resolution, that is, at the particle or contact level. The variables described at this level are usually discrete, but they might be also continuum inspired, like particle stress. Particle stress is a representative or notional average grain stresses, computed from contact forces (O’Sullivan, 2011).

Figure 13 represents, for a vertical slice of the $\mathrm{CC}$, the vertical particle stress component 461 side by side with the network of contact forces (CF) at the same stage. Forces exceeding the whole ensemble average $(\mu)$ are plotted in dark grey if $\mathrm{CF}<\mu+5 \sigma$ while they are in black 
463 if $\mathrm{CF}>\mu+5 \sigma$ where $\sigma$ is the standard deviation. The forces smaller than the average force 464 are plotted in light gray. The lines join the centroids of contacting spheres and their thickness 465 is proportional to the magnitude of the normal force.

466 When the CPT is performed in a loose material under $100 \mathrm{kPa}$, many free spaces are 467 visible within the granular mass. Particles are less constrained when pushed by the cone and 468 zones of highly stressed particles are then relatively small. Differences between the crushable 469 and non-crushable case, almost negligible at the macroscale, (Figure 12), are also small at the 470 microscale. The contact force networks of the uncrushable and crushable material appear very 471 similar also in correspondence of horizontal sections above (section A-A*) and below (section $472 \quad \mathrm{~B}-\mathrm{B}^{*}$ ) of the cone tip (Figure 14).

473 The situation is different for the CPT on the denser specimens (Figure 15). A cluster of 474 highly stressed particles appears below the cone tip in this dense case. The size of this cluster 475 is far larger in the non-crushable material than in the crushable one. The strong contact force 476 network appears rarefied in the crushable material just in the area below the tip where the 477 highest particle stresses appear in the uncrushable material (section B-B*, Figure 16). This 478 suggest that it is in that particular zone crushing takes place (CPT induced). In the non479 crushable material strong force chains that emanate from the cone tip are able to reach further 480 into the chamber. When crushing is enabled the vertical pattern of strong force chains 481 associated with the chamber principal stress axis appears less disrupted by cone intrusion. 482 Behind the cone tip (section A-A*, Figure 16) the rarefication of strong force chains in the 483 crushable case is also clear. The implications of this for side friction are outside the scope of 484 this paper.

485 Crushing takes place both before CPT (during initial chamber stress set-up) and during 486 cone penetration. It is interesting to compare the spatial localization of the crushing events 487 that take place during these two separate simulation phases. In Figure 17 the location of 488 crushed particles in two orthogonal chamber slices is represented for the compression phase, 489 previous to CPT, in the dense specimen under $200 \mathrm{kPa}$. It is apparent that crushing events are 490 evenly distributed within the chamber. Representing now only the particles crushed during the 491 CPT phase for the same test a very different pattern appears (Figure 18). Most crushing events 
have taken place within 2-3 radius from the cone. This is in agreement with the pattern suggested by the force network and particle stress in Figure 15.

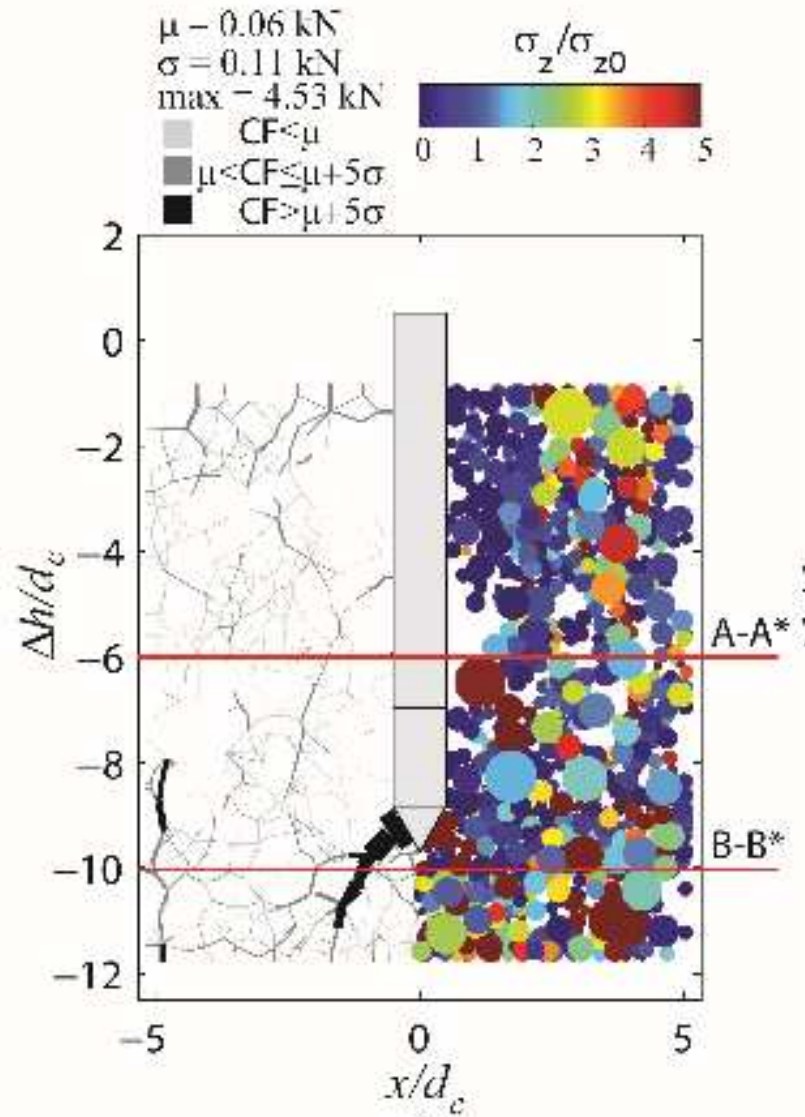

a)

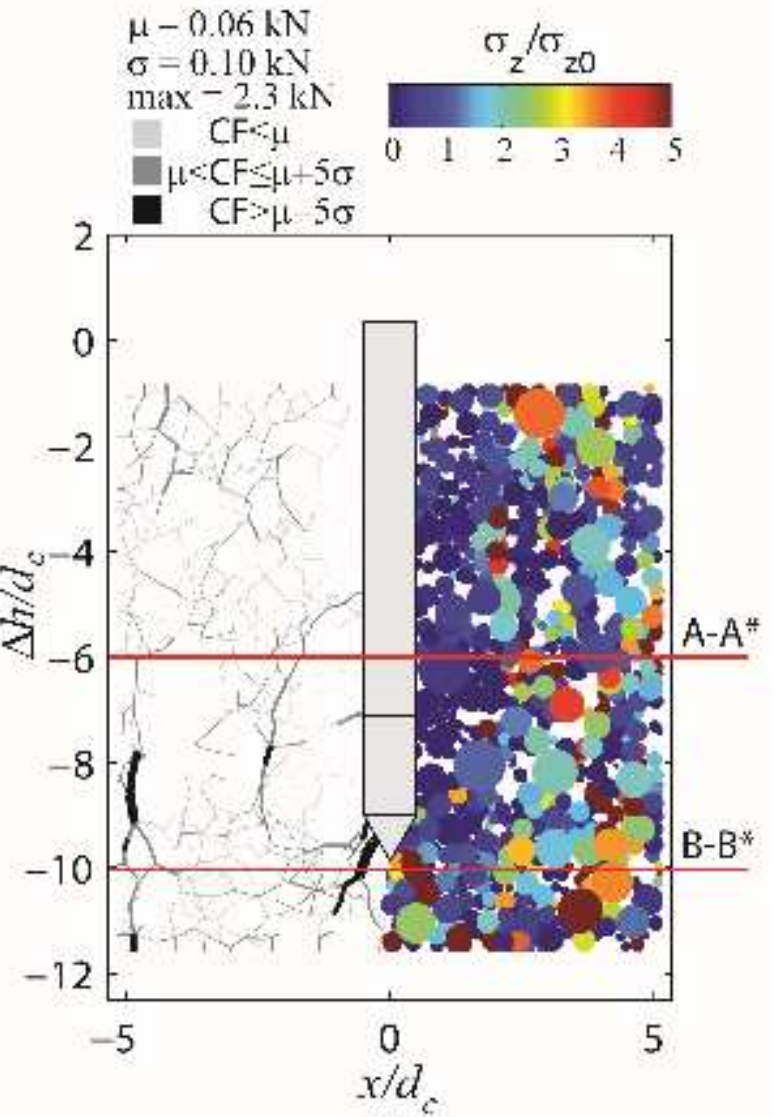

b)

Figure 13 CPT on a) uncrushable and b) crushable loose specimens at $\sigma_{\mathrm{z} 0}=100 \mathrm{kPa}$ applied vertical stress. Left half: contact forces. Right half: particle vertical stress normalised by applied vertical stress $\sigma_{\mathrm{z} 0}$. 


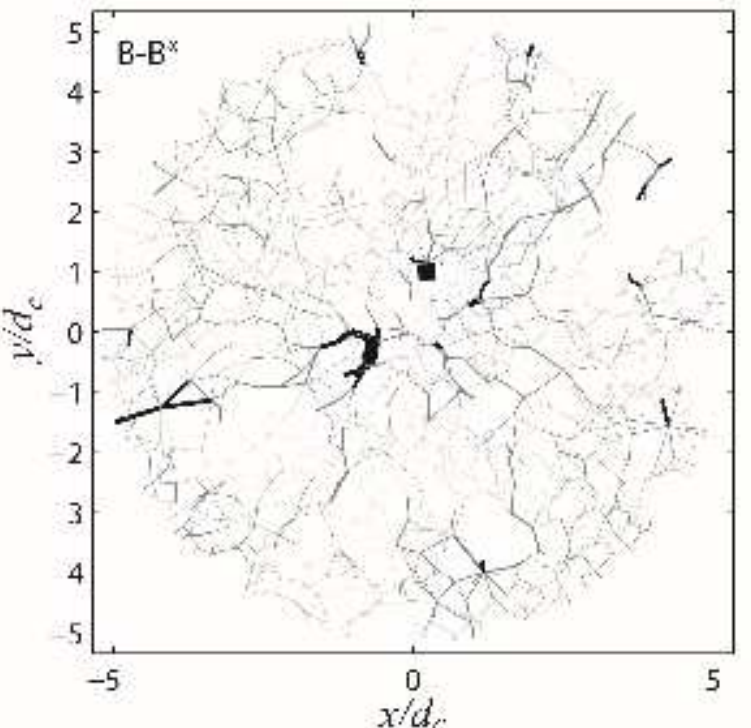

a)

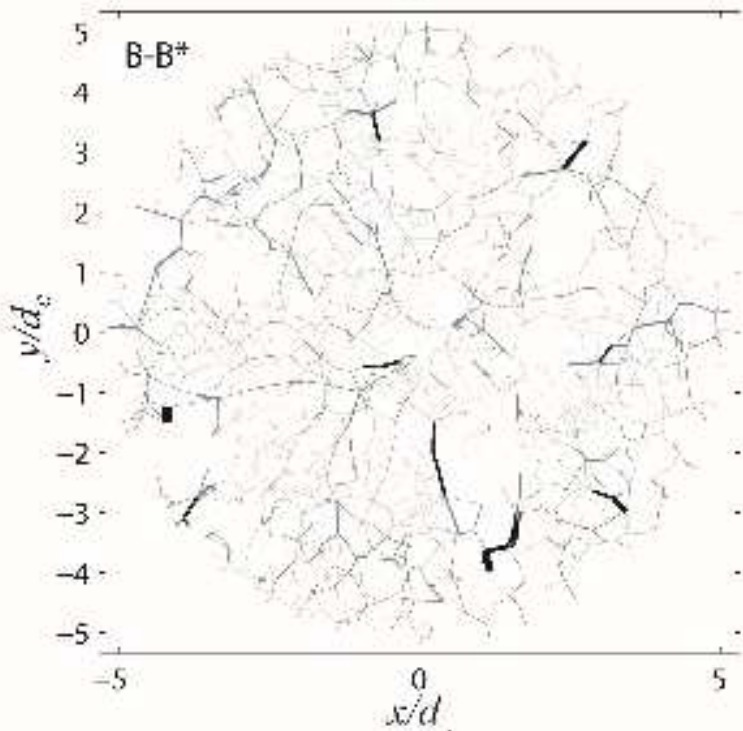

c)

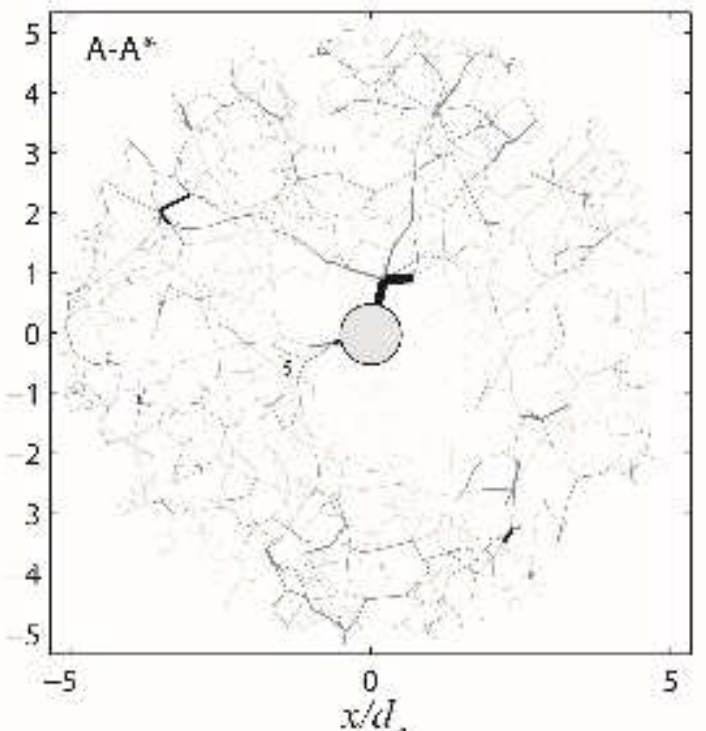

b)

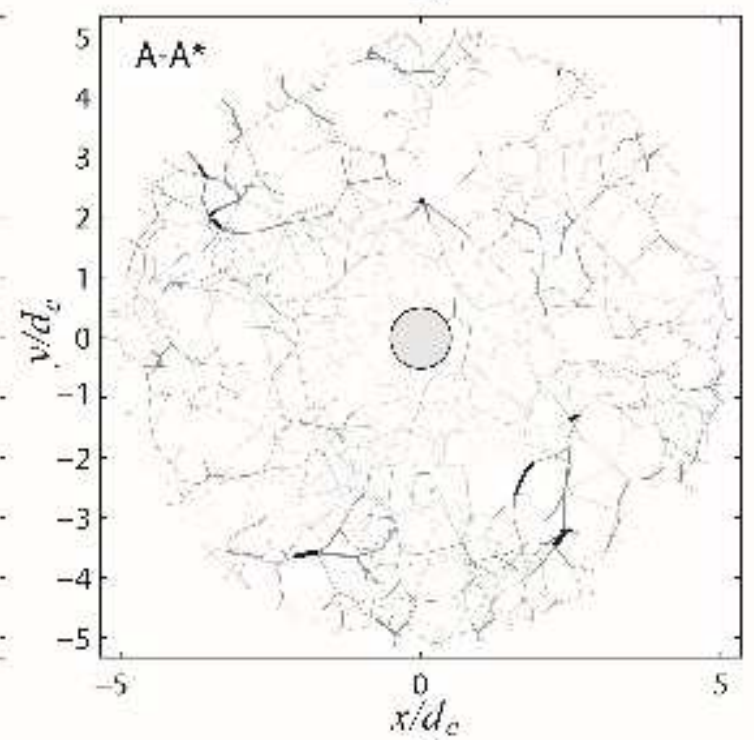

d)

Figure 14 Particle contact forces for loose uncrushable (a,b) and loose crushable (c,d) in sections $A-A^{*}$ and $B-B^{*}$ shown in Figure 13. 


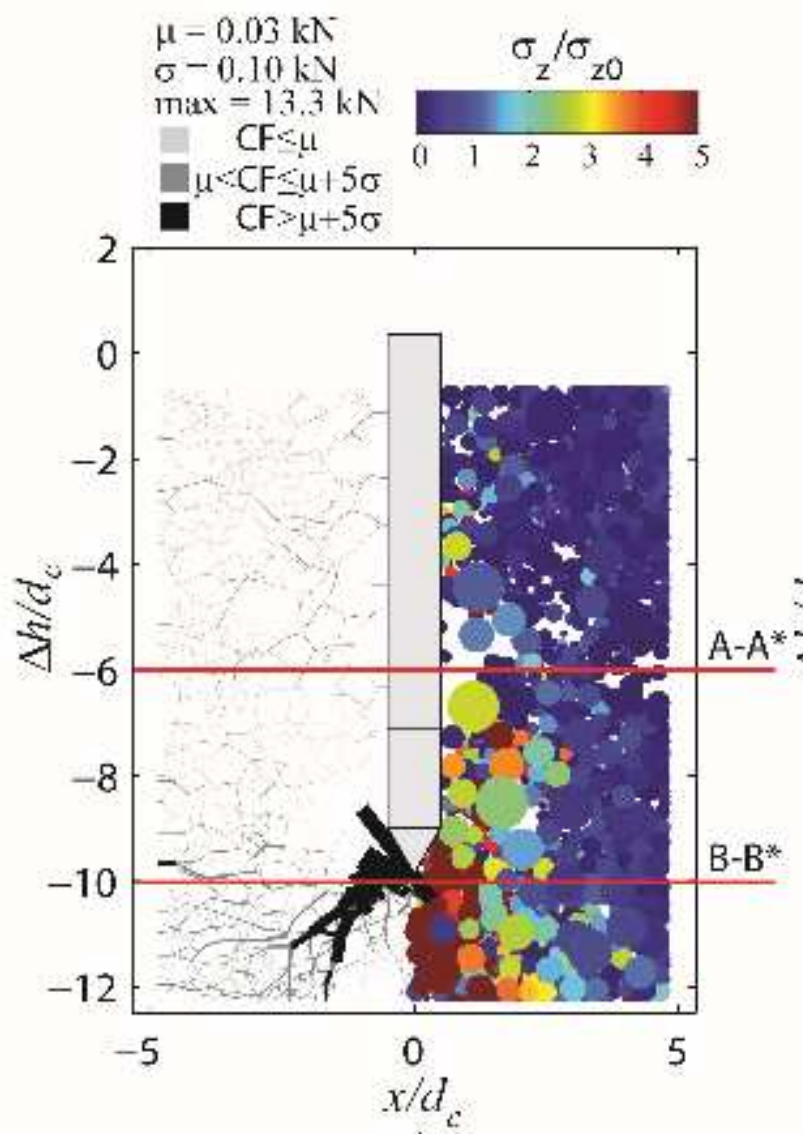

a)

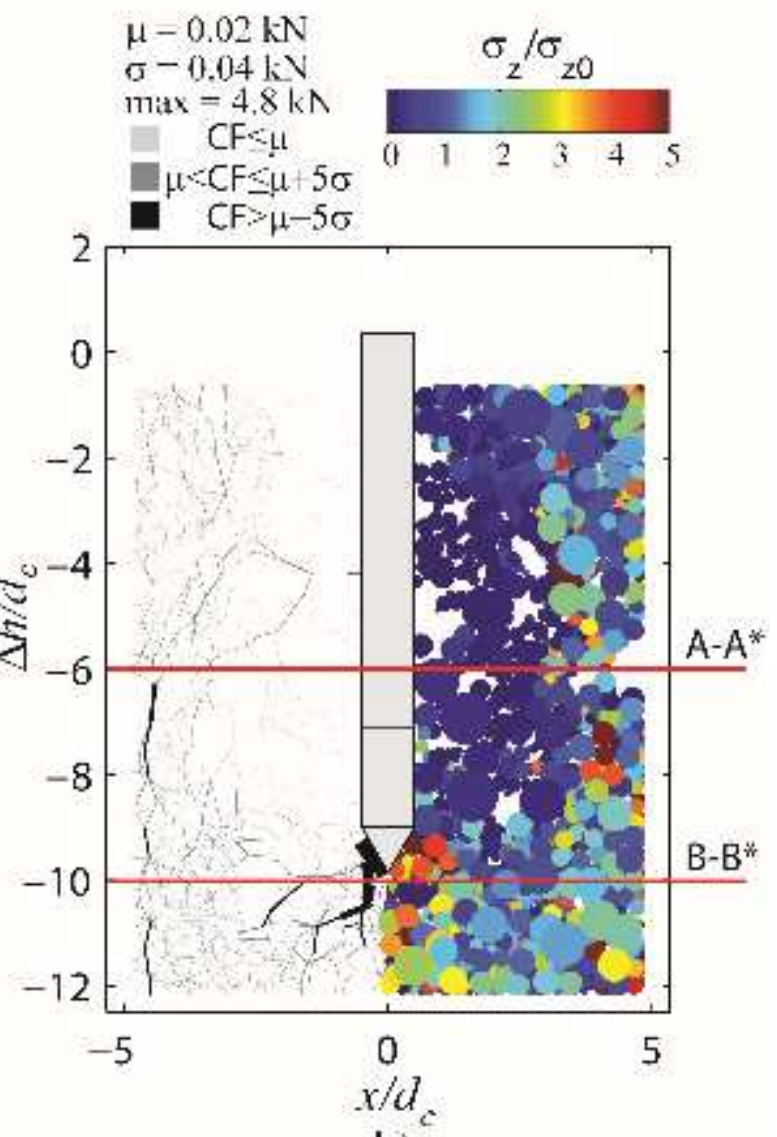

b)

Figure 15 CPT on a) uncrushable and b) crushable dense specimens at $\sigma_{\mathrm{z} 0}=100 \mathrm{kPa}$ applied vertical stress. Left half: contact forces. Right half: particle vertical stress normalised by applied vertical stress $\sigma_{\mathrm{zo}}$. 


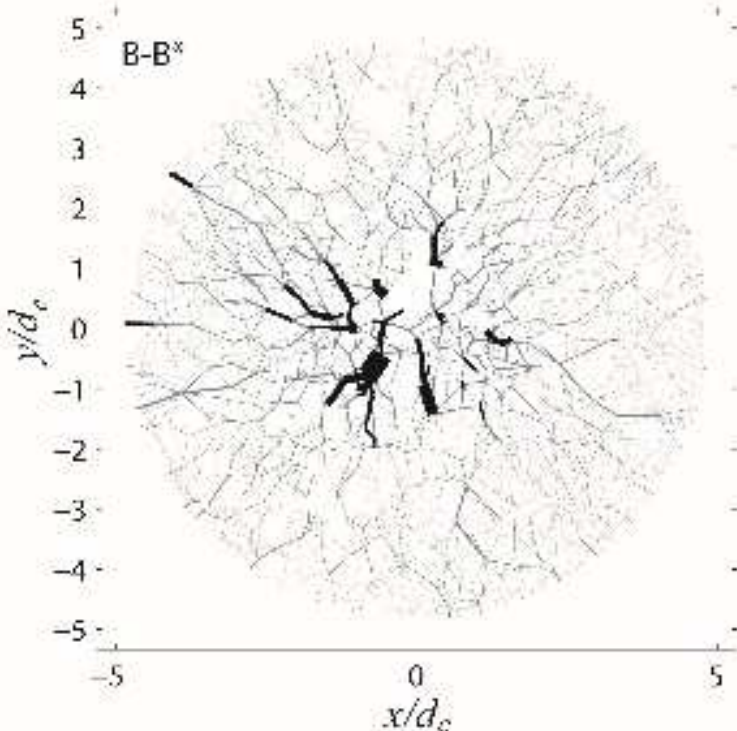

a)

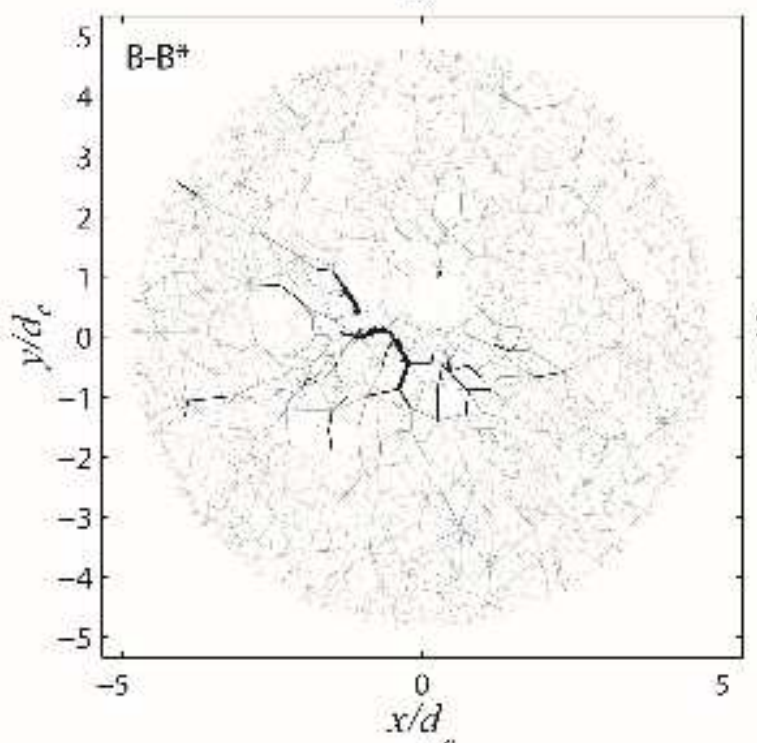

c) ${ }^{6}$

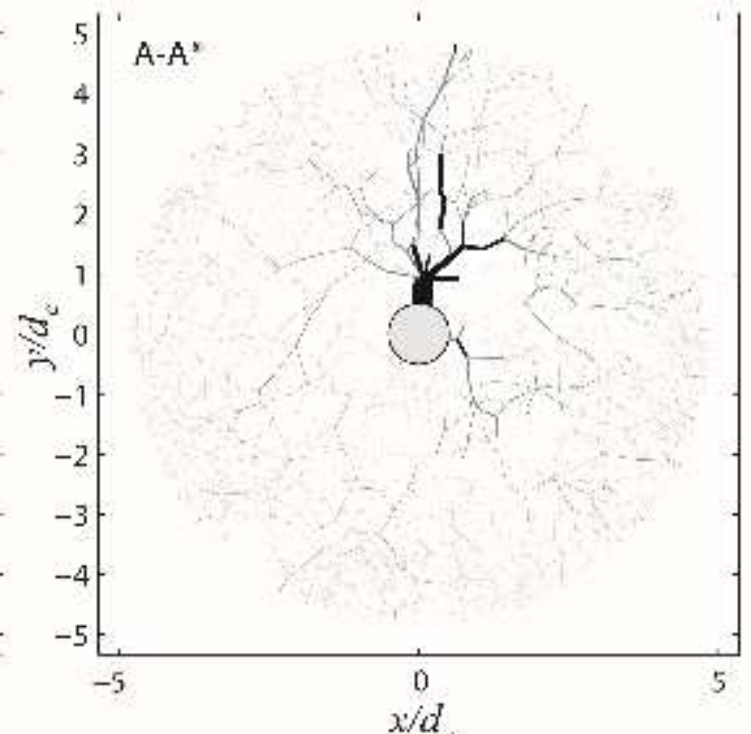

b)

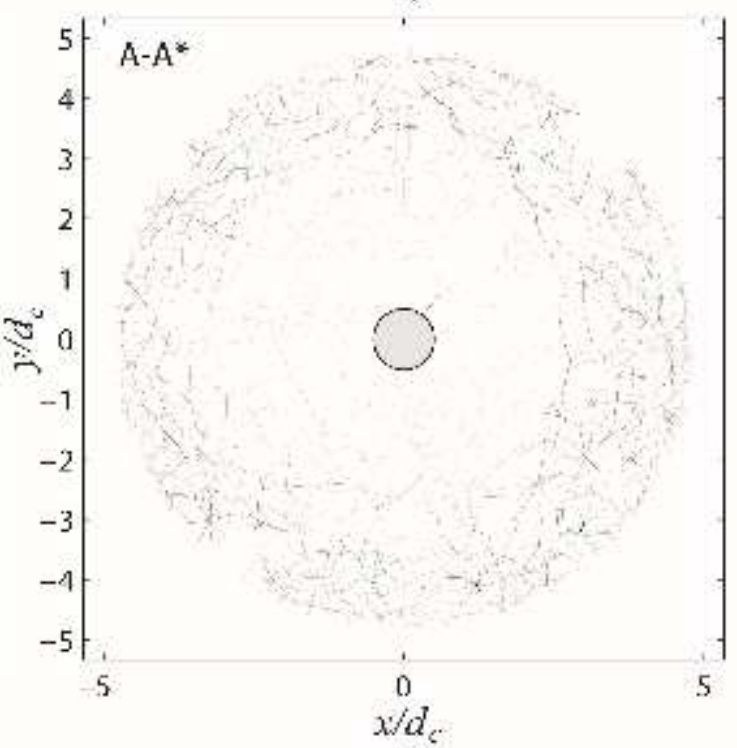

d)

Figure 16 Particle contact forces for dense uncrushable (a,b) and dense crushable $(c, d)$ in 515 sections $A-A *$ and $B-B *$ shown in Figure 15 


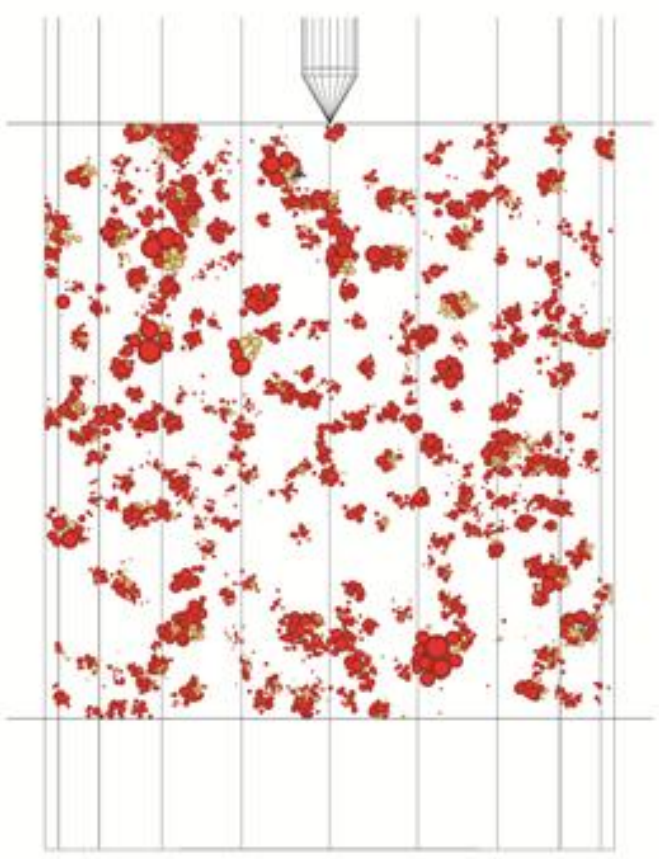

a)

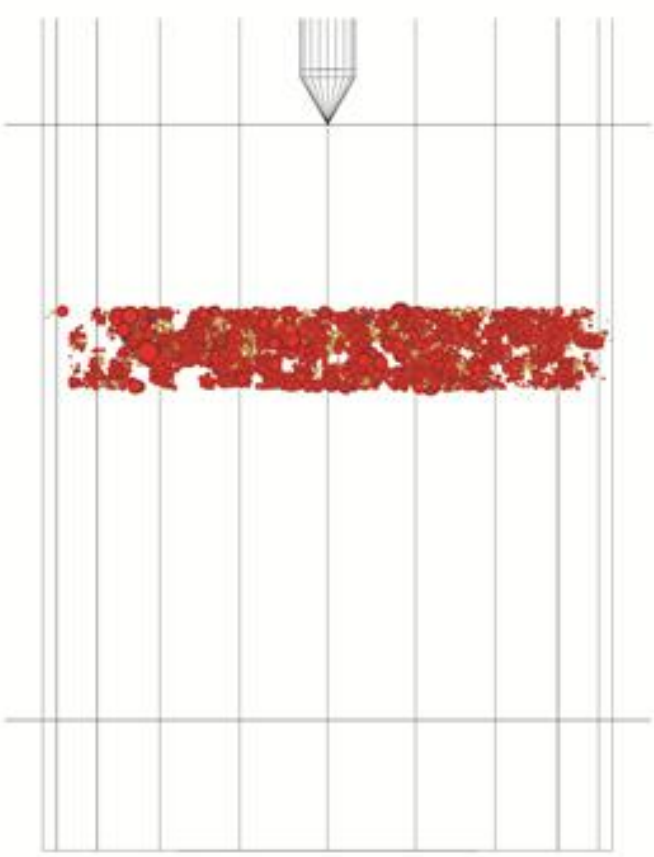

c)

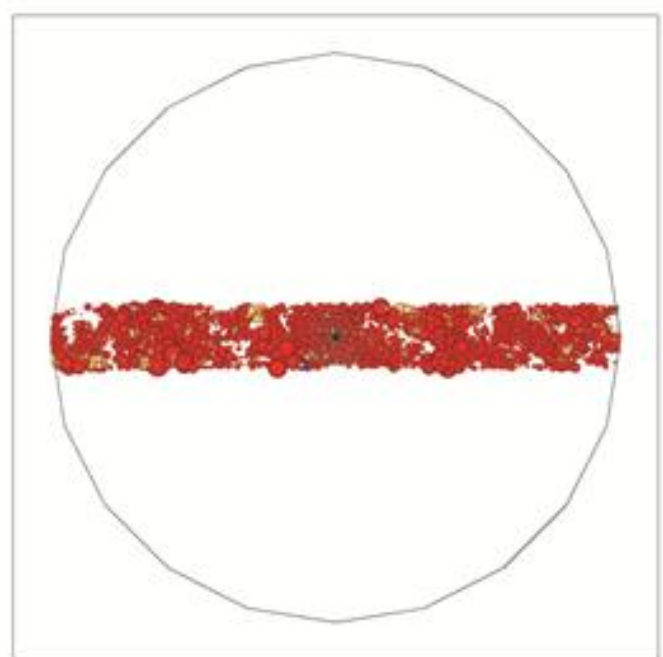

b)

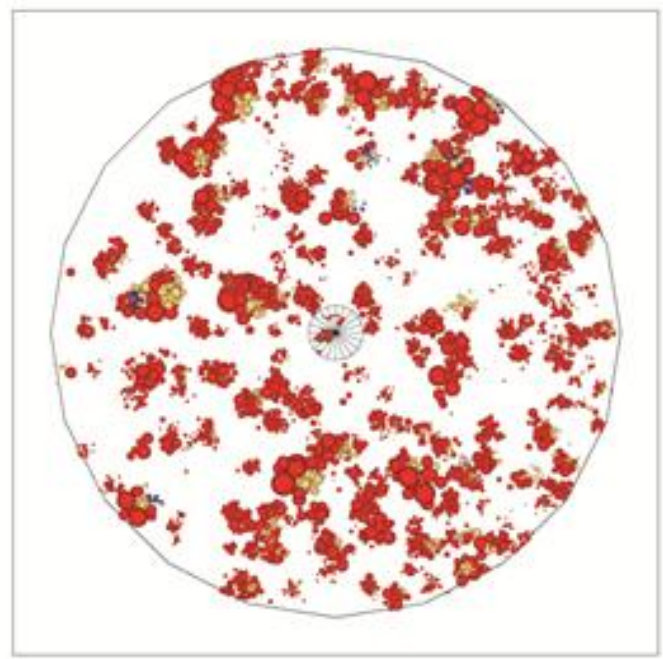

d)

517 Figure 17 Crushed particles during stress initialization (before CPT) for the dense specimen at vertical stress $200 \mathrm{kPa}$ (a) horizontal projection of particles crushed within a vertical slice (b) vertical projection of particles crushed within a vertical slice (c) horizontal projection of particles crushed within a horizontal slice (d) vertical projection of particles crushed within a horizontal slice. 


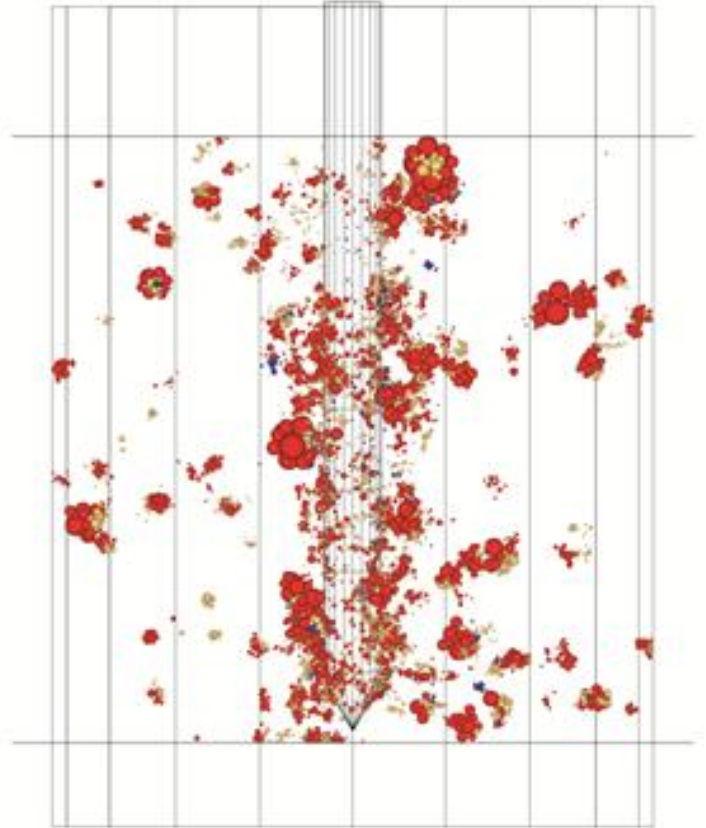

a)

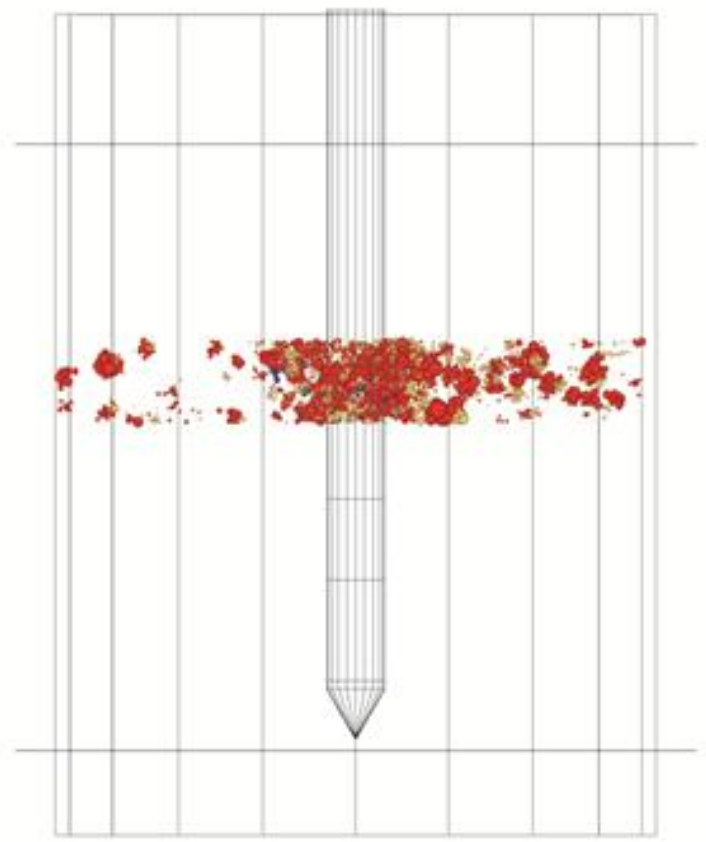

c)

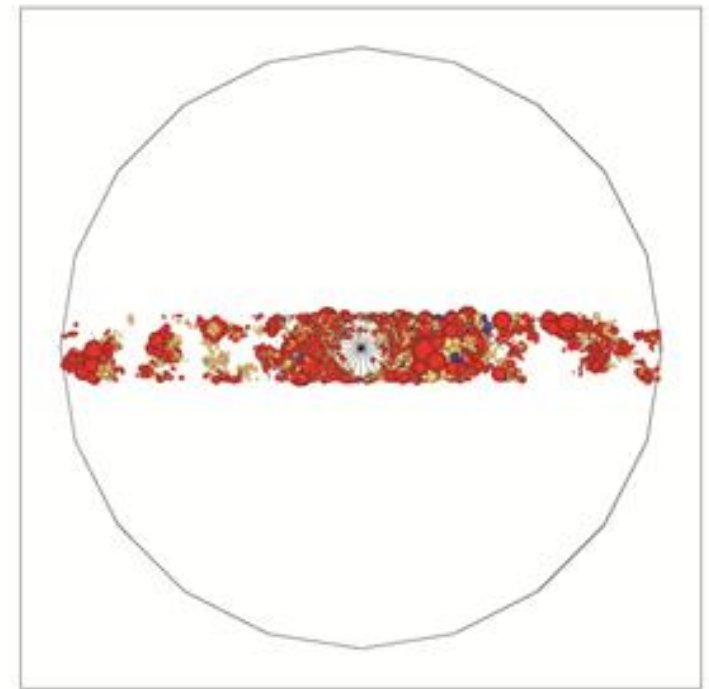

b)

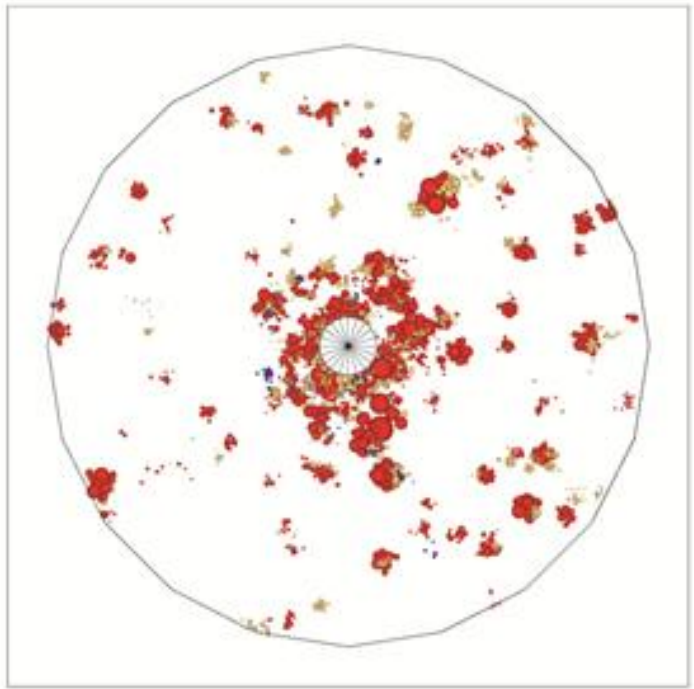

d)

Figure 18 Crushed particles during CPT for the dense specimen at vertical stress $200 \mathrm{kPa}$ (a) horizontal projection of particles crushed within a vertical slice (b) vertical projection of particles crushed within a vertical slice (c) horizontal projection of particles crushed within a horizontal slice (d) vertical projection of particles crushed within a horizontal slice. 


\section{6. Discussion}

528 The simulations resulted in values of cone tip resistance that, as observed by Wesley 529 (2007), were practically insensitive to initial density. When crushing is disabled in the 530 numerical simulations cone tip resistance is multiplied by a factor ranging between 1 and 4 , a

531 factor that increases with density and vertical confinement stress. Both Almeida et al. (1991) 532 and Wesley (2007) reported comparisons of CPT in crushable sand with parallel tests in less 533 crushable materials. Of course, in their experiments two different sands were compared 534 (Ticino and Quiou for Almeida et al.; Silica and Pumice for Wesley (2007)), and other factors 535 might have changed, whereas in the simulations here the only change was that of crushability. 536 When plotted against initial relative density, the ratios obtained in the simulation compare 537 well with those observed in the experiments (Figure 19). Note that relative density for the 538 Wesley (2007) CC data is obtained as average of that reported for same stress silica and 539 pumice tests. Relative density values for the DEM simulations are assigned assuming valid 540 the extreme $\gamma_{d}$ values for pumice $\left(620\right.$ and $\left.730 \mathrm{~kg} / \mathrm{m}^{3}\right)$ reported in Wesley (2007). The

541 different specimen formation procedures followed in the laboratory and in the simulation 542 explain DEM values are above $100 \%$ 


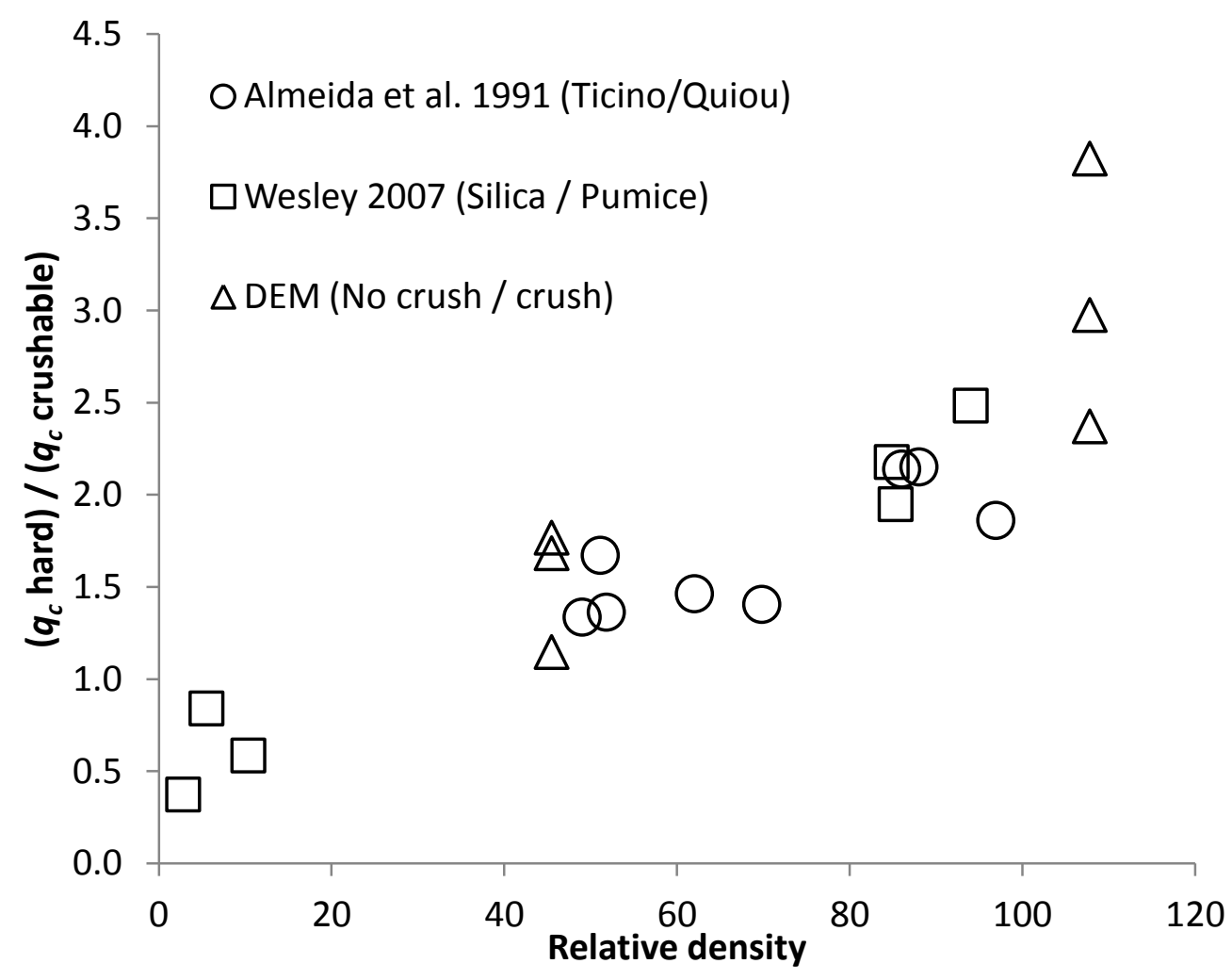

543

544

545

546

Figure 19 Effect of crushability on cone tip resistance.

Despite these remarkable coincidences, the magnitude of cone tip resistance for the crushable material in the simulations is smaller, approximately by a factor of 3 , than that observed by Wesley (2007) in his experiments (compare, for instance, the result in Figure 1 to the similar test in Figure 11). There are several possible causes that explain that discrepancy. Three that seem important are (a) parameter calibration (b) mass loss (c) scaling.

The calibration process described was only approximate, lacking for instance particlescale crushing information for pumice sand. The performance on the model in the element tests was acceptable, but, for instance the peak strength of the dense triaxial specimen was somewhat underestimated, by some $10 \%$ (Figure 9). This may have impacted on the CPT results but it is unlikely to explain most of the observed difference.

In the experiments there was no mass loss on crushing. To check the effect of lost volume in the CPT simulations, some replica tests were run. In the replica tests a particle that reached the crushing condition was simply deleted from the simulation instead of partly replaced with 14 smaller particles. This more than doubled the percentage of particle volume lost at each crushing event. The effect of that modification on the penetration curves was small (Figure 20). 


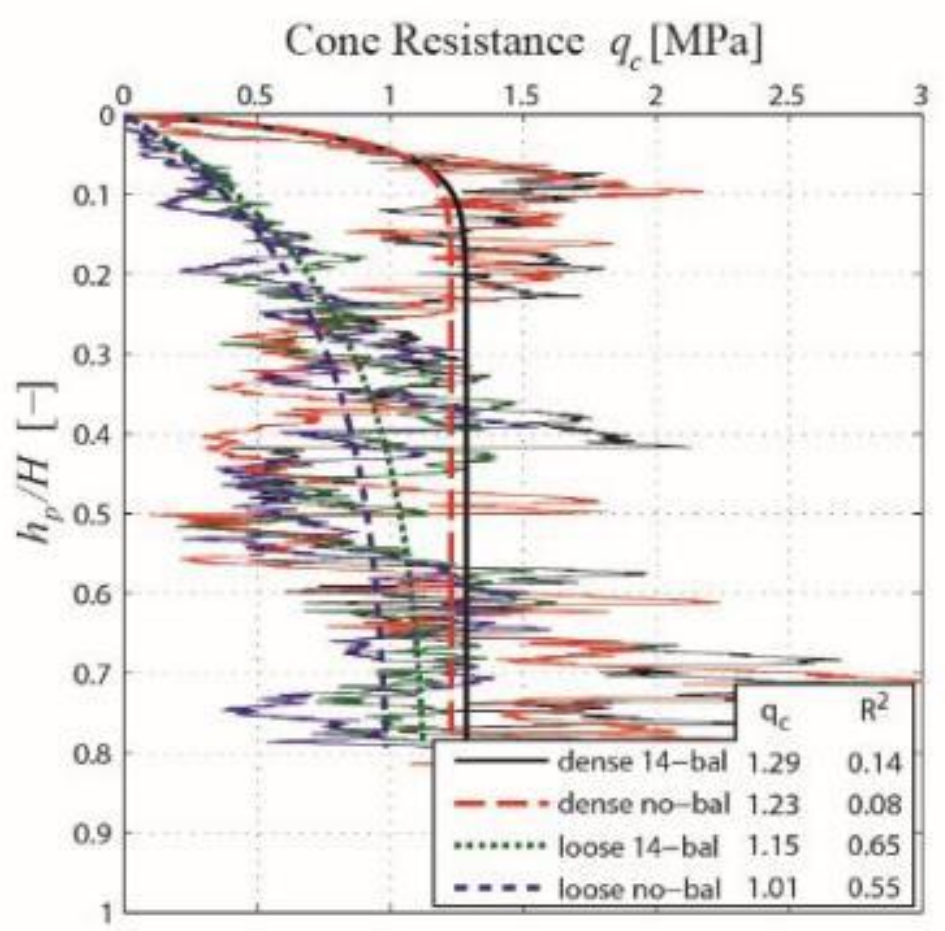

Figure 20 Effect of the mass loss upon breakage on the penetration curves for the cases when vertical stress is $200 \mathrm{kPa}$.

In fact, the mass loss during the simulations is also relatively small. Table 6 compiles the percentage of crushing events during the simulations. The number of initial particles that is crushed during the simulations remains always below $3.5 \%$ of the initial number. The percentages of crushing events during the CPT phase do not seem very sensible to initial density or boundary stress. Crushing of the original particles is larger during the initial stress installation phase, than during the penetration phase. The amount of loss mass during the simulations is consequently small, always below $5 \%$ in total and below $2 \%$ during the actual penetration test.

With respect to scaling there are two different aspects to consider. Scaling of particle size is unlikely to have much effect per se: Arroyo et al. (2011) obtained closer agreement with experimental results using a larger scaling factor (50). On the other hand, at least a sizeable part of this discrepancy can be attributed to the different chamber to cone diameter ratio, $\left(R_{d}\right.$, see Table 3).

It is well known that the $R_{d}$ ratio has a major effect on the penetration value in a way that depends on the specimen density and boundary conditions applied in the chamber (Butlanska 
et al. 2010b). Several corrections have been proposed in the literature to account for $R_{d}$ effect

581 (Mayne \& Kulhawy, 1991; Jamiolkowski et al. 2003). Most results referred to stresscontrolled conditions, but Parkin and Lunne, (1982) while testing dense silica sand under no

583 lateral strain conditions, indicated a factor of 2 in cone resistance as $R_{d}$ doubled from 25 to 50 .

584 Here the experimental $\mathrm{R}_{\mathrm{d}}$ also doubles that of the numerical model; it is then possible that 585 chamber/cone size effect would explain most of the observed difference between experiments 586 and simulations.

587 To further explore this hypothesis a numerical experiment was devised. A new virtual 588 chamber (Table 3, column "DEM Large") was built using a non-scaled cone to obtain the same $R_{d}=21$ that was prevailing in the experiments. A smaller cone required a smaller particle scaling factor, to keep cone/particle ratio large enough. This resulted in a computationally costly model (more than $2 \times 10^{5}$ first generation particles).

This larger model was run at high density under vertical confinement of 50 and $200 \mathrm{kPa}$, with and without crushing. Aligned with previous results, the reduction on $q_{c}$ induced by crushing in this large chamber case is given approximately by a factor of 2 (Figure 21a,b). For the $200 \mathrm{kPa}$ case, the full experimental curve was available. A very good match with the corresponding numerical simulation is observed. Chamber/cone relative size has a dominant role (Figure 21c,d) explaining the differences noted before between the absolute values of tip 599 resistance in the experiment and in the main simulation series.
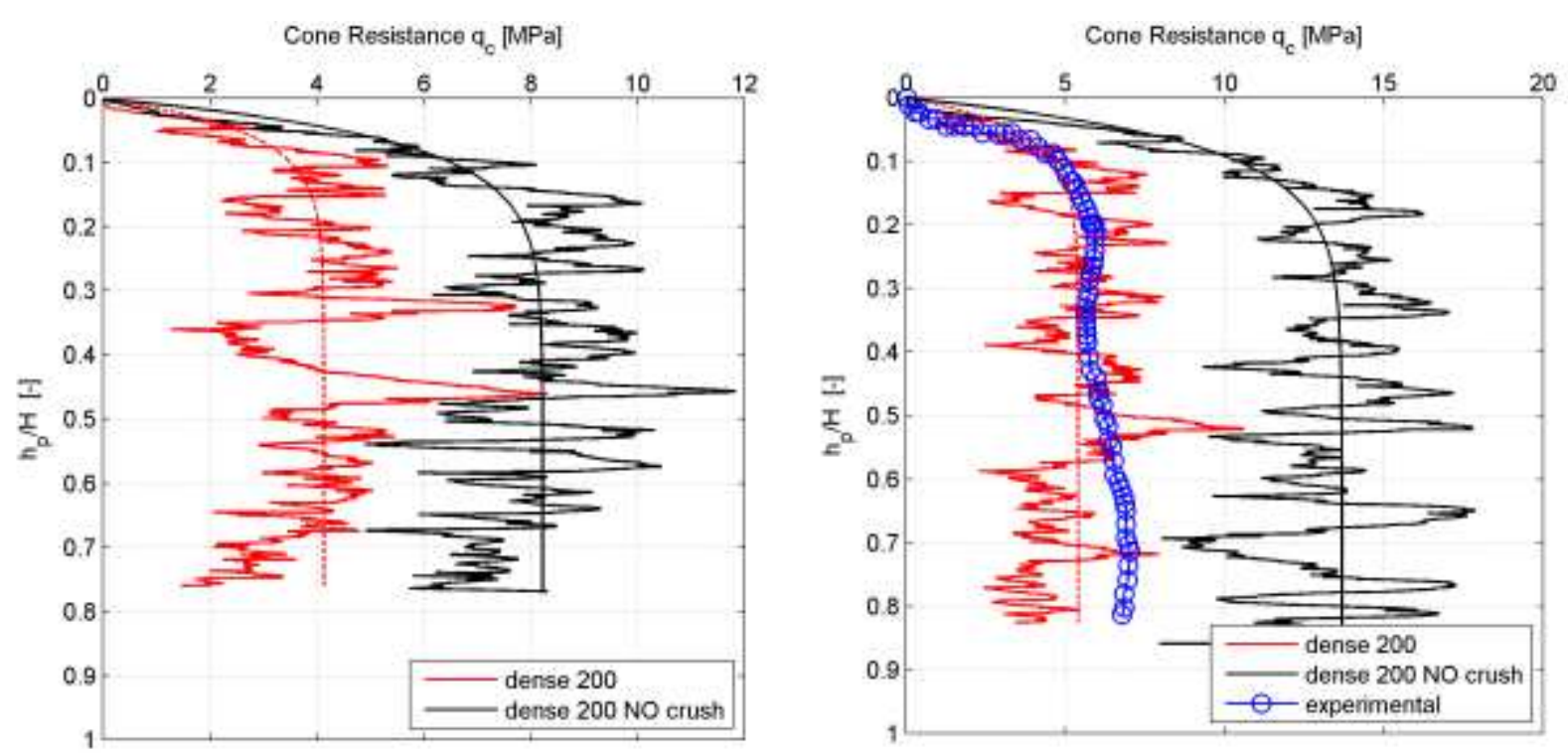
(a) $\sigma_{\mathrm{z} 0}=50 \mathrm{kPa}$

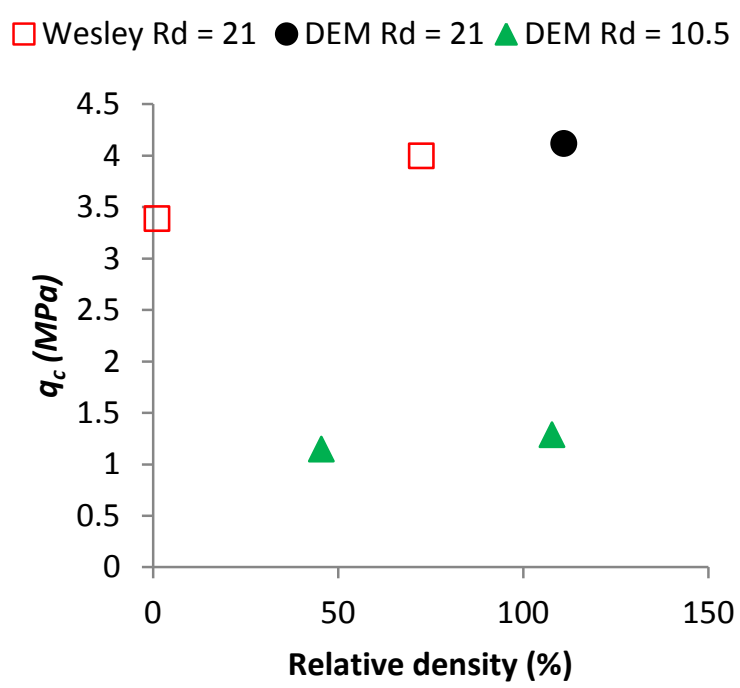

(b) $\sigma_{\mathrm{z} 0}=200 \mathrm{kPa}$

$\square$ Wesley $R d=21 \bullet D E M R d=21 \triangle D E M R d=10.5$

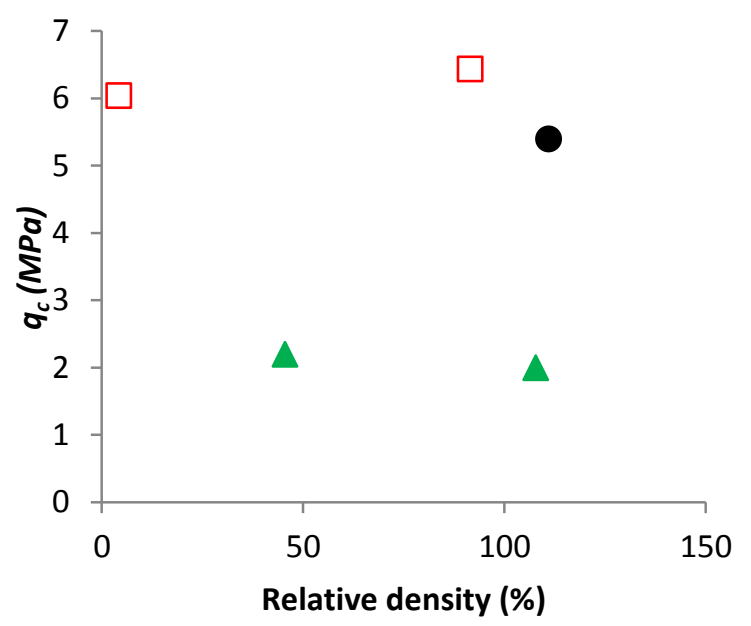

(d) $\sigma_{\mathrm{z} 0}=200 \mathrm{kPa}$

600 Figure 21 Chamber/cone size effect: (a)-(b) Raw and adjusted penetration curves for CPT 601 performed in crushable and uncrushable material under two different confining stress, $602 \sigma_{\mathbf{z} 0}=50 \mathrm{kPa}$ and $200 \mathrm{kPa}$, respectively; (c)-(d) adjusted cone tip resistance values for the tests 603 shown above. 


\section{Conclusions}

It has been shown how analogue discrete models of crushable soils can be built using enhanced DEM models. Soils may crush even without having porous grains, but soils that have porous grains are generally more crushable. Incorporating internal grain porosity requires a proper definition of porosity fractions and some attention to the fact that internal porosity may be grain-size dependent. It is perhaps more difficult to exactly measure such dependency in experiments than to incorporate it into a discrete model.

Extrapolation of single-specimen behavior to calibration chamber behavior requires scaling to limit computational costs. Scaling makes the comparison with experimental CC tests difficult, because some important geometric ratios of the problem are changed. Numerical chamber filling procedures are unlike experimental ones and may produce different fabrics and result in somewhat inhomogeneous specimens. Despite all these severe procedural limitations, it appears that the effect of crushability on cone tip resistance that is predicted by the simulations here presented is remarkably similar to what has been observed on previous experimental work. Thus the DEM analysis results in cone tip resistances that are practically insensitive to initial density. Also, the computed ratio between cone tip resistance of non-crushable and crushable pumice sand is quite similar to reported experimental values over a range of relative densities. Quantitative agreement was also obtained with Wesley's experimental tip resistance results running models with a non-scaled cone.

Macroscopic agreement with experimental observations offers credence to microscopic observations that are simply extracted from discrete models but which have difficult direct experimental verification. A limited amount of microscale exploration of the simulations has been presented here. It suggests that most particle crushing during cone penetration occurs at some distance below the cone tip. It does also indicate that crushing reduced the length of the strong force chains radiating from the cone tip into the chamber. Crushing also disrupts the strong force network behind the cone tip, close to the shaft, where newly created particles accumulate. The microscopic results suggest that in crushable soils the cone feels mostly the material that its own insertion has created. The effect on simulated cone shaft resistance of crushing is currently under investigation. 
634 Finally, it is noted that, although not directly addressed here, similar observations on the 635 effect of crushability on driven pile tip resistance have been reported (e.g. Kuwajima et al. 636 2009). It is then likely that the approach presented here would also prove useful for that kind 637 of problem.

638 


\section{Appendix: porosity corrections}

640 If the value of internal porosity for all particles, $n_{\text {int }}$, is constant, intragranular porosity 641 can be expressed as:

$642 \quad n^{\mathrm{intra}}=\frac{\sum n_{\mathrm{int}} V_{T}^{p}}{V_{T}}=n_{\mathrm{int}} \frac{\sum V_{T}^{p}}{V_{T}}=n_{\mathrm{int}}\left(1-n^{\mathrm{inter}}\right)$

643 from this and the fact that $n=n^{\text {inter }}+n^{\text {intra }}$ follows

$644 n=1-\left(1-n^{\text {inter }}\right)\left(1-n_{\text {int }}\right)$

645 If internal porosity is variable, but a unique value of internal porosity $\bar{n}_{\text {int }}$ is assumed, 646 intragranular porosity is only approximately computed. The difference between the exact 647 value and the approximate value of intragranular porosity is given by a correction term, $\Delta n$

$648 \quad \bar{n}^{\text {intra }}=n^{\text {intra }}+\Delta n$

649 The correction term is given by

$650 \Delta n=\frac{1}{V_{T}}\left[\sum_{p} V_{T}^{p} n_{\mathrm{int}}^{p}-\bar{n}_{\mathrm{int}} \sum_{p} V_{T}^{p}\right]=n^{\mathrm{int} r a}-\bar{n}^{\mathrm{int} r a}$

Only if $\bar{n}_{\text {int }}$ is selected as the volume-weighted particle porosity average, the correction

652 term is 0 . A relation analogous to (21) is still valid

653

$\bar{n}^{\mathrm{intra}}=\bar{n}_{\text {int }}\left(1-n^{\mathrm{inter}}\right)$

654

655

Apparent and real porosities are related through the assumed value of internal particle 656 porosity $\bar{n}_{\text {int }}$, since 


$$
\begin{aligned}
& n^{*}=1-\frac{\gamma_{d}}{\gamma_{w} \bar{G}_{s}}=\frac{\left(1-\bar{n}_{\mathrm{int}}\right) G_{s 0}-(1-n) G_{s 0}}{\left(1-\bar{n}_{\mathrm{int}}\right) G_{s 0}}=\frac{\left(n-\bar{n}_{\mathrm{int}}\right)}{\left(1-\bar{n}_{\mathrm{int}}\right)} \\
& n=\left(1-\bar{n}_{\mathrm{int}}\right) n^{*}+\bar{n}_{\mathrm{int}}
\end{aligned}
$$

658 The question now is how to relate this apparent porosity $\mathrm{n}^{*}$ with the value of intergranular 659 porosity $n^{\text {inter }}$ that is requested to build a DEM model. We have

$660 \bar{n}-\Delta n=\left(1-\bar{n}_{\mathrm{int}}\right) n^{*}+\bar{n}_{\mathrm{int}}$

661 Combining the precedent expressions, and after some manipulation, the following relation 662 is obtained

$663 \quad n^{\text {inter }}=n^{*}+\frac{\Delta n}{\left(1-\bar{n}_{\text {int }}\right)}$

664

665

666 


\section{9. ACKNOWLEDGEMENTS}

668 This work has been supported by the Ministry of Science and Innovation of Spain through 669 the research grants BIA2011-27217 and BIA2014-59467-R 670 


\section{10. REFERENCES}

672 Ahmed, S. M., Agaiby, S. W. \& Abdel-Rahman, A. H. (2014). A unified CPT-SPT 673 correlation for non-crushable and crushable cohesionless soils. Ain Shams Engineering Journal 5(1), pp. 63-73.

Almeida, M., Jamiolkowski, M. \& Peterson, R., (1991). Preliminary result of CPT tests in

676

677

678

679

680

681

682

683

684

685

686

687

688

689

690

691

692

693

694

695

696

697

698 calcareous Quiou sand. Proceedings of the International Symposium on Calibration Chamber Testing, Elsevier, New York, pp. 41-53.

Arroyo, M., Butlanska, J., Gens, A., Calvetti, F. \& Jamiolkowski, M. (2011). Cone penetration tests in a virtual calibration chamber. Géotechnique 61 (6), pp. 525-531

Arroyo, M., Butlanska, J. \& Gens, A. (2013). Effect of radial walls on CPT in DEM-based Virtual Calibration Chamber. Proceedings of the $3^{\text {rd }}$ International Symposium on Computational Geomechanics (COMGEO III), Krakow, Poland

Ben-Nun, O. \& Einav, I. (2010). The role of self-organization during confined comminution of granular materials. Philosophical Transactions of the Royal Society A: Mathematical, Physical and Engineering Sciences, Vol. 368, pp. 231-247.

Bolton, M. D., Nakata, Y. \& Cheng, Y. P. (2008). Micro- and macro-mechanical behaviour of DEM crushable materials. Géotechnique 58(6), pp. 471-480.

Bruchmüller J., Van Wachem B.G.M., Gua, S. \& Luo K.H. (2011). Modelling discrete fragmentation of brittle particles. Powder Technology 208, pp. 731-739

Brzesowsky, R. H., Spiers, C. J., Peach, C. J. \& Hangx, S. J. T. (2011). Failure behavior of single sand grains: Theory versus experiment. Journal of Geophysical Research: Solid Earth (1978-2012), 116(B6).

Butlanska, J., Arroyo M. \& A. Gens (2010a). Virtual Calibration Chamber CPT tests on Ticino sand. 2nd International Symposium on Cone Penetration Testing, CPT'10, Huntington Beach, California, pp. 217-224

Butlanska, J., Arroyo M. \& A. Gens (2010b). Size effects on a virtual calibration chamber. 7th European Conference on Numerical Methods in Geotechnical Engineering, NUMGE 2010, Trondheim, pp. 225-230 
699

700

701

702

703

704

705

706

707

708

709

710

711

712

713

714

715

716

717

718

719

720

721

722

723

724

725

726

727

Butlanska, J., Arroyo, M., Gens, A. \& O'Sullivan, C. (2013). Multiscale analysis of CPT in a virtual calibration chamber. Canadian Geotechnical Journal 51(1), pp. 51-66 [doi: 10.1139/cgj-2012-0476]

Butlanska, J., Arroyo M. \& A. Gens (2014a). Steady state of solid-grain interfaces during simulated CPT. Studia Geotechnica et Mechanica 35(4), pp. 13-22 [doi: 10.2478/sgem2013-0034]

Butlanska, J. Arroyo, M. \& Gens, A. (2014b). Probing DEM specimen heterogeneity by simulated CPT, International Symposium from Micro to Macro, Cambridge 2014, Taylor \& Francis, pp. 269 - 274

Casini, F., Viggiani, G. M. \& Springman, S. M. (2013). Breakage of an artificial crushable material under loading. Granular matter 15(5), pp. 661-673

Cheng, Y. P., Nakata, Y. \& Bolton, M. D. (2003). Discrete el-ement simulation of crushable soil. Géotechnique 53(7), pp. 633-641

Ciantia, M. O., Arroyo, M., Calvetti, F. \& Gens, A. (2014a). Particle failure in DEM models of crushable soil response. Numerical Methods in Geotechnical Engineering, pp. 345350 (ISBN: 978-1-138-00146-6)

Ciantia, M. O., Arroyo, M., Butlanska, J. \& Gens, A. (2014b). DEM modelling of a double-porosity crushable granular material. In K. Soga et al. (Ed.), Proc. of IS-Cambridge 2014 Int. Symposium on Geomechanics from Micro to Macro, p 269-274 Taylor \& Francis Group, London,

$I S B N$

978-1-138-02707-7.

\section{http://www.crcpress.com/product/isbn/9781138027077}

Ciantia, M. O., Castellanza, R. \& di Prisco, C. (2014c). Experimental study on the waterinduced weakening of calcarenites. Rock Mechanics and Rock Engineering 48, pp. 441-461.

Ciantia, M. O., Arroyo, M., Calvetti, F. \& Gens, A. (2015). An approach to enhance efficiency of DEM modelling of soils with crushable grains. Géotechnique 65(2), pp. 91-110.

Einav, I. (2007). Breakage mechanics_-part I: theory. J. Mech. Phys. Solids 55, pp. 1274 1297 [doi:10.1016/j.jmps.2006.11.003]

Esnault, V. P. B. \& Roux, J. N. (2013). 3D numerical simula-tion study of quasistatic grinding process on a model granu-lar material. Mechanics of Materials 66, pp. 88-109 
Gabrieli, F., Cola, S. \& Calvetti, F. (2009). Use of an up-scaled DEM model for analysing the behaviour of a shallow foundation on a model slope. Geomechanics and Geoengineering: An International Journal 4(2), pp. 109- 122

Itasca (2010). Particle flow code in three dimensions: Software manual. Minnesota, MN, USA

Jamiolkowski, M., Lo Presti, D. C. F. \& Manassero, M. (2003). Evaluation of relative density and shear strength of sands from CPT and DMT. Soil Behavior and Soft Ground Construction.

Jansen, U. \& Stoyan, D. (2000). On the validity of the Weibull failure model for brittle particles. Granular Matter 2(4), pp. 165-170.

Kuwajima, K., Hyodo, M. \& Hyde, A. F. (2009). Pile bearing capacity factors and soil crushabiity. Journal of geotechnical and geoenvironmental engineering 135(7), pp. 901-913.

Lin, J. \& W. Wu (2012). Numerical study of miniature penetrometer in granular material by discrete element method, Philosophical Magazine 92(28-30), pp. 3474-3482

Lobo-Guerrero, S. \& Vallejo, L. E. (2005). DEM analysis of crushing around driven piles in granular materials. Géotechnique, 55(8), pp. 617-623

Lunne, T., Robertson, P. K. \& Powell, J. J. (1997). Cone penetration testing in geotechnical practice. CRC Press

Marketos, G. \& Bolton, M. D. (2009). Compaction bands simulated in discrete element models. J. Struct. Geol. 31(5), pp. 479-490

Mayne, P.W. and Kulhawy, H. (1991). Calibration chamber database and boundary effects corrections for CPT data. In Proceedings of the 1st International Symposium on Calibration

\section{Chamber Testing, pp. 1257-1264, Postdam, N.Y., 1991}

McDowell, G.R. \& de Bono, J. P. (2013). On the micro mechanics of one-dimensional normal compression. Géotechnique 63(11), pp. 895-908

McDowell, G. R., Falagush, O. \& Yu, H. S. (2012). A particle refinement method for simulating DEM of cone penetration testing in granular materials. Géotechnique Letters 2(July-September), pp. 141-147 
Meier, T., \& Wehr, J. (2014). Influence of the calcite content of sands on the CPTresistance. NUMGE 2014, 8th Conference on Numerical Methods in Geotechnical Engineering in Delft, The Netherlands, 18-20 June 2014

Minh, N. H. \& Cheng, Y. P. (2013). A DEM investigation of the effect of particle-size distribution on one-dimensional compression, Géotechnique 63(1), pp. 44-53

Moss, R.E.S. (2014). A Critical State framework for seismic soil liquefaction triggering using CPT, 3rd International Symposium on Cone Penetration Testing, CPT14, May 12-14, 2014 - Las Vegas, Nevada, Paper 2\#20

O’Sullivan, C. (2011). Particulate discrete element modelling. Taylor \& Francis.

Parkin, A.K., \& Lunne, T., (1982). Boundary effects in the laboratory calibration of a cone penetrometer for sand. Proceedings of the Second European Symposium on Penetration Testing, Amsterdam, 761-768

Quezada, J. C., Breul, P., Saussine, G. \& Radjai, F. (2014). Penetration test in coarse granular material using Contact Dynamics Method. Computers and Geotechnics 55, pp. 248253.

Robertson, P. K. (2009). Interpretation of cone penetration tests-a unified approach. Canadian Geotechnical Journal 46(11), pp. 1337-1355

Russell, A. R. \& Muir Wood, D. (2009). Point load tests and strength measurments for brittle spheres. International Journal of Rock Mechanics And Mining Sciences 46, pp. 272280

Russell, A. R., Muir Wood, D. \& Kikumoto, M. (2009). Crushing of particles in idealised granular assemblies. J. Mech. Phys. Solids 57(8), pp. 1293-1313

Schnaid, F. (2009). In situ testing in geomechanics: the main tests. CRC Press.

Ting, J. M., Corkum, B. T., Kauffman, C. R. \& Greco, C. (1989). Discrete numerical model for soil mechanics. Journal of Geotechnical Engineering 115(3), pp. 379-398

Tran, Q.A., Chevalier B. \& Breul, P. (2014). A numerical study of the penetration test at constant rod velocity, Computer Methods and Recent Advances in Geomechanics - Oka, Murakami, Uzuoka \& Kimoto (Eds.), Taylor \& Francis Group 193-198

Wehr, W., (2005). Influence of the carbonate content of sand on vibro-compaction. Proceedings of the 6th International Conference on Ground Improvement Techniques, Coimbra, Portugal, pp. 625-632. 
Weibull, W. (1951). A statistical distribution function of wide applicability. Journal of Applied Mechanics 18, pp. 293-297

Wesley L. D. (2007). Geotecnical characteristics of a pumice sand. Characterisation and

791 Engieering properties of Natural Soils - Tan, Phoon, Hight \& Leroueil (eds). ISBN 978-0792 415-42691-6

793 Wesley, L. D. (2001). Determination of specific gravity and void ratio of pumice 794 materials. ASTM Geotechnical Testing Journal 24(4), pp. 418-422.

795 Zhang, C., Nguyen, G.D., \& Einav, I. (2013). The end-bearing capacity of piles penetrating into crushable soils, Géotechnique 63 (5), pp. 341: 354

797 Zhao, Z. (2013). Gouge particle evolution in a rock fracture undergoing shear: a microscopic 798 DEM study. Rock Mechanics and Rock Engineering 46(6), pp. 1461-1479

799 Zhao, Z. \& Song, E-x. (2015). Particle mechanics modeling of creep behavior of rockfill 800 materials under dry and wet conditions. Computers and Geotechnics 68, pp. 137-146 
802 11. Tables

803 Table 1 Specimen tests: initial states. Inferred values in cursive

804

\begin{tabular}{|c|c|c|c|c|c|c|}
\hline Case & Test ID & $\boldsymbol{n}^{*}$ & $\begin{array}{c}\gamma_{\boldsymbol{d}} \\
\left(\mathbf{k g} / \mathbf{m}^{\mathbf{3}}\right)\end{array}$ & $\boldsymbol{n}$ & $\boldsymbol{n}^{\text {inter }}$ & $\boldsymbol{n}^{\text {intra }}$ \\
\hline Experiment & "Dense" & 0.55 & 805 & 0.69 & 0.33 & 0.37 \\
\hline Experiment & "Loose" & 0.59 & 722 & 0.72 & 0.37 & 0.35 \\
\hline DEM & "Dense" & 0.53 & 740 & 0.72 & 0.33 & 0.38 \\
\hline DEM & "Loose" & 0.59 & 665 & 0.74 & 0.39 & 0.35 \\
\hline
\end{tabular}

805 Table 2 Calibrated model parameters for pumice sand

\begin{tabular}{|c|c|c|c|c|c|c|}
\hline $\begin{array}{c}\phi \\
{[\mathbf{r a d}]}\end{array}$ & $\begin{array}{c}\boldsymbol{G} \\
{[\mathbf{k P a}]}\end{array}$ & $\begin{array}{c}v \\
{[-]}\end{array}$ & $\begin{array}{c}\sigma_{\text {lim,0 }} \\
{[\mathbf{k P a}]}\end{array}$ & $\begin{array}{c}\text { var } \\
{[-]}\end{array}$ & $\begin{array}{c}\boldsymbol{m} \\
{[-]}\end{array}$ & $\begin{array}{c}\boldsymbol{d}_{\boldsymbol{0}} \\
{[\mathbf{m m}]}\end{array}$ \\
\hline 0.4 & $3.33 \times 10^{5}$ & 0.3 & $1.16 \times 10^{5}$ & 0.5 & 5 & 2 \\
\hline
\end{tabular}

806

807

Table 3 Comparative geometrical characteristics of experimental and simulated CC

\begin{tabular}{|l|l|c|c|c|}
\hline Variable (unit) & Symbol & Experiment & DEM-base & DEM-large \\
\hline Chamber diameter $(\mathrm{mm})$ & $D_{C}$ & 760 & 760 & 760 \\
\hline Cone diameter $(\mathrm{mm})$ & $d_{c}$ & 36 & 72.1 & 35.6 \\
\hline Chamber height $(\mathrm{mm})$ & $H$ & 910 & 900 & 760 \\
\hline Particle mean size $(\mathrm{mm})$ & $D_{50}$ & 1 & 22 & 15 \\
\hline Chamber/cone diameter ratio & $\left(D_{C} / d_{c}\right)=R_{d}$ & 21 & 10.5 & 21 \\
\hline Cone /particle ratio & $\left(d_{c} / D_{50}\right)=n_{p}$ & 36 & 3.3 & 2.4 \\
\hline Friction sleeve height $(\mathrm{mm})$ & $h_{s}$ & 133 & 133 & 133 \\
\hline Number of particles at $5 \mathrm{kPa}$ & - & - & 55385 & 203000 \\
\hline
\end{tabular}

808

809

Table 4 CC initial states. Inferred values in cursive

\begin{tabular}{|c|c|c|c|c|c|c|c|c|}
\hline \multirow{2}{*}{ Test ID } & $\begin{array}{c}\sigma_{z 0} \\
(\mathbf{P a})\end{array}$ & $\begin{array}{c}\sigma_{\mathrm{h} 0} \\
(\mathbf{k P a})\end{array}$ & $\begin{array}{c}\gamma_{d} \\
\left(\mathbf{k g} / \mathbf{m}^{\mathbf{3}}\right)\end{array}$ & $\begin{array}{c}\boldsymbol{n} \\
(-)\end{array}$ & $\begin{array}{c}\boldsymbol{n}^{\text {inter }} \\
(-)\end{array}$ & $\begin{array}{c}\gamma_{d} \\
\left(\mathbf{k g} / \mathbf{m}^{\mathbf{3}}\right)\end{array}$ & $\begin{array}{c}\boldsymbol{n} \\
(-)\end{array}$ & $\begin{array}{c}\boldsymbol{n}^{\text {inter }} \\
(-)\end{array}$ \\
\hline Dense 50 & 50 & 25 & 696 & 0.73 & 0.39 & 740 & 0.72 & 0.33 \\
\hline Dense 100 & 100 & 40 & 697 & 0.73 & 0.39 & 740 & 0.72 & 0.33 \\
\hline Dense 200 & 200 & 72 & 720 & 0.72 & 0.37 & 740 & 0.72 & 0.33 \\
\hline Loose 50 & 50 & 28 & 621 & 0.76 & 0.43 & 665 & 0.74 & 0.39 \\
\hline Loose 100 & 100 & 49 & 629 & 0.76 & 0.42 & 665 & 0.74 & 0.39 \\
\hline Loose 200 & 200 & 76 & 624 & 0.76 & 0.43 & 665 & 0.74 & 0.39 \\
\hline
\end{tabular}


Table 5 Parameters for the penetration curve adjusted to each simulated CPT

\begin{tabular}{|l|l|l|l|l|l|l|}
\cline { 2 - 8 } \multicolumn{1}{c}{} & \multicolumn{3}{l}{ Crush } & No-Crush & \multicolumn{2}{l|}{} \\
\hline Test ID & $\mathrm{a}$ & $\mathrm{b}$ & $\mathrm{R}^{2}$ & $\mathrm{a}$ & $\mathrm{b}$ & $\mathrm{R}^{2}$ \\
\hline Dense 50 & 1.29 & 35.6 & 0.14 & 3.06 & 35.5 & 0.27 \\
\hline Dense 100 & 1.69 & 39.5 & 0.15 & 5.03 & 19.5 & 0.54 \\
\hline Dense 200 & 2.00 & 39.6 & 0.15 & 7.65 & 11.8 & 0.56 \\
\hline Loose 50 & 1.15 & 5.0 & 0.65 & 1.32 & 7.3 & 0.60 \\
\hline Loose 100 & 1.36 & 11.0 & 0.54 & 2.29 & 7.0 & 0.79 \\
\hline Loose 200 & 2.20 & 9.3 & 0.55 & 3.89 & 8.9 & 0.65 \\
\hline
\end{tabular}

813

814

815

816

817

\begin{tabular}{|c|l|l|l|l|}
\hline Density & Vertical Stress & Phase & $\begin{array}{l}\text { Crushing events in phase } \\
\text { / initial particle number }\end{array}$ & $\begin{array}{l}\text { Crushing events in phase / } \\
\text { phase } \\
\text { initial particle }\end{array}$ \\
\hline nense & 50 & compression & $1.7 \%$ & $1.7 \%$ \\
\hline Dense & 100 & compression & $2.4 \%$ & $2.4 \%$ \\
\hline Dense & 200 & compression & $3.3 \%$ & $3.5 \%$ \\
\hline Dense & 50 & CPT & $1.6 \%$ & $2.2 \%$ \\
\hline Dense & 100 & CPT & $1.4 \%$ & $2.1 \%$ \\
\hline Dense & 200 & CPT & $1.1 \%$ & $1.7 \%$ \\
\hline Loose & 50 & compression & $1.8 \%$ & $2.0 \%$ \\
\hline Loose & 100 & compression & $2.5 \%$ & $3.0 \%$ \\
\hline Loose & 200 & compression & $3.5 \%$ & $4.8 \%$ \\
\hline Loose & 50 & CPT & $1.0 \%$ & $1.5 \%$ \\
\hline Loose & 100 & CPT & $1.1 \%$ & $1.7 \%$ \\
\hline Loose & 200 & CPT & $1.4 \%$ & $2.0 \%$ \\
\hline
\end{tabular}




\section{$820 \quad$ 12. List of symbols}

821

822

$\varepsilon_{z}$ is vertical deformation

823

$\varepsilon_{v o l}$ is volumetric deformation

824

$\sigma_{c}$ is compressive strength

825

$\sigma_{t}$ is tensile strength

826

$\sigma_{c}(d)$ is compressive strength as function of particle diameter

827

$\sigma_{c}(d=2 \mathrm{~mm})$ is compressive strength for a $2 \mathrm{~mm}$ diameter particle

828

$\sigma_{t}(d)$ is tensile strength as function of particle diameter

829

$\sigma_{t}(d=2 \mathrm{~mm})$ is tensile strength for a $2 \mathrm{~mm}$ diameter particle

830

$v$ is the Poisson's ratio

831

$v_{1}$ and $v_{2}$ are the Poisson ratio of the contacting spheres

832

$\theta_{0}$ is a solid angle 'seen' from the center of the particle

$833 \phi$ is the interparticle friction angle

$834 \sigma_{\lim }$ is the limit strength

$835 \sigma_{\lim , 0}$ is the mean limit strength

$836 \quad \sigma_{z 0}$ is the chamber's vertical confinement stress

$837 \sigma_{\mathrm{h} 0}$ is the chamber's horizontal initial confinement stress

$838 \quad \sigma_{\mathrm{z}}$ is the vertical stress

$839 \sigma$ is the CF standard deviation

$840 \mu$ is the CF ensemble average

841

$\gamma_{d}$ is the dry unit weight

842

$\gamma_{w}$ is the unit weight of water

843

$844 \quad A$ is a fitting parameter

$845 a$ is a fitting parameter

$846 \quad A_{F}$ is the contact area 
$B$ is a fitting parameter

$848 \quad b$ is a fitting parameter

$849 \quad \mathrm{CC}$ is calibration chamber

$850 \quad \mathrm{CF}$ is contact force

$851 \quad d$ is the particle diameter

$852 d_{0}$ is the reference diameter (chosen as $2 \mathrm{~mm}$ )

$853 \quad d_{\text {limit }}$ is the comminution limit

$854 d_{1}$ and $d_{2}$ are the diameters of the two spheres in contact

$855 \quad d_{\mathrm{c}}$ cone diameter

$856 \quad D_{\mathrm{c}}$ chamber diameter

$857 \quad D_{50}$ is the mean particle diameter

$858 E_{1}$ and $E_{2}$ are the Young modulus of the contacting spheres

$859 \quad f_{1}$ is the strength correction factor 1

$860 f_{2}$ is the strength correction factor 2

$861 \quad F$ is the magnitude of the normal contact force

$862 \quad F_{n}$ is the normal and shear contact force component

$863 \quad F_{t}$ is the shear contact force component

$864 \quad F_{\lim }$ is the magnitude of the limit normal contact force

$865 G_{s 0}$ specific gravity of quartz

$866 G_{s}(d)$ is the apparent specific gravity of a particle with diameter $d$

$867 \bar{G}_{s}$ is the constant apparent specific gravity

$868 \quad G$ is the shear modulus

869 GSD is the grain size distribution

$870 \quad H$ is the chamber height

$871 \quad h_{\mathrm{s}}$ is the friction sleeve height

$872 \quad h_{p}$ is the penetration depth

$873 \quad k_{N}$ normal contact stiffness

$874 \quad k_{S}$ tangential contact stiffness

$875 \quad m$ is a material parameter

$876 \quad \mathrm{~N}$ is the scaling factor 
$877 \quad n$ is the total porosity

$878 \quad n_{\text {int }}$ is the internal porosity

$879 \quad n_{\text {int }}^{p}$ is the internal porosity of particle $p$

$880 n^{\text {inter }}$ is the total volume fraction not occupied by particles

$881 n^{\text {intra }}$ is the total volume fraction occupied by internal voids

$882 \bar{n}_{\text {int }}$ is the constant internal porosity

$883 \bar{n}^{\text {intra }}$ is the approximate value of $n^{\text {intra }}$

$884 n^{*}$ is the apparent porosity

$885 n_{p}$ is the cone/mean particle diameter ratio

$886 q_{c}$ is the cone tip resistance

$887 \quad r_{H}$ is the radius of the contact area

$888 R_{d}$ is the Chamber/cone diameter ratio

$889 r_{1}$ and $r_{2}$ are the radius of the contacting spheres

$890 \quad r$ is the sphere radius

$891 U$ is the sphere overlap

892 var coefficient of variation

$893 \quad V_{V}^{p}$ is the volume of the voids within particle $p$

$894 \quad V_{T}^{p}$ is the total volume of particle $p$

$895 \quad V_{S}^{p}$ is the solid volume for particle $p$

$896 V_{T}$ is the total volume

$897 \quad V_{s}$ total solid volume for a collection of $p$ particles

898

899 